\title{
Apropiación y control estatal de ambientes de altura en el extremo meridional del Tawantinsuyu
}

\section{Appropiation and State control on high-altitude environments in Southern border of Tawantinsuyu}

\author{
Víctor Alberto Durán ${ }^{1}$ (D) https://orcid.org/0000-0002-0534-0739 \\ Sol Zárate Bernardi ${ }^{1}$ (D) https://orcid.org/0000-0002-9124-1090

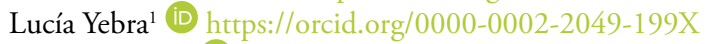 \\ Cecilia Frigolé ${ }^{\text {(DD }}$ https://orcid.org/0000-0002-2163-792X \\ Gustavo Lucero $^{1,2}$ (D) https://orcid.org/0000-0002-4687-3929 \\ Diego Andreoni ${ }^{3}$ (D) https://orcid.org/0000-0002-9975-240X \\ Diego Winocur ${ }^{4}$ (D) https://orcid.org/0000-0001-8354-7818 \\ Alejandra Gasco ${ }^{1}$ (D) https://orcid.org/0000-0003-2670-1377 \\ Erik Marsh ${ }^{1}$ (iD) https://orcid.org/0000-0003-2355-5415 \\ Silvina Castro $^{1}$ (D) https://orcid.org/0000-0002-0868-1715 \\ María Inés Zonana ${ }^{1}$ (D) https://orcid.org/0000-0002-3318-5668 \\ Ramiro Barberena ${ }^{1}$ (D) https://orcid.org/0000-0002-4323-1197 \\ Valeria Cortegoso $^{1}$ (D) https://orcid.org/0000-0003-3361-815X
}

${ }^{1}$ Laboratorio de Paleoecología Humana, Instituto Interdisciplinario de Ciencias Básicas, CONICET-Universidad Nacional de Cuyo. Mendoza, ARGENTINA. Email: duranvic2@gmail.com; zaratebernardisol@gmail.com; yebralucia@hotmail.com; cfrigole@gmail.com; soljandra@gmail.com; erik.marsh@gmail.com; silcastro24@hotmail.com; inezonana@gmail.com; ramidus28@gmail.com; vcortegoso@gmail.com

${ }^{2}$ Departamento de Antropología, Facultad de Ciencias Sociales y Humanidades,

Universidad Católica de Temuco, CHILE. Email: glucero18@gmail.com

${ }^{3}$ División Arqueología, Facultad de Ciencias Naturales y Museo, Universidad Nacional de La Plata, CONICET. La Plata, Buenos Aires, ARGENTINA. Email: andreondieg@hotmail.com

${ }^{4}$ Instituto de Estudios Andinos. Departamento de Ciencias Geológicas, Facultad de Ciencias Exactas y Naturales, Universidad de Buenos Aires-CONICET. CABA, ARGENTINA.

Email: diegowinocur@hotmail.com 


\title{
Resumen
}

Se presentan resultados sobre técnicas constructivas y patrones de ocupación del espacio, cronología, tecnología lítica, tipología y tecnología cerámica, zooarqueología de camélidos, antracología y arte rupestre, correspondientes a un conjunto de sitios arqueológicos del Área Natural Protegida Laguna del Diamante (Mendoza, Argentina). Esta área se ubica en la cordillera Principal y vincula las cuencas altas de los ríos Diamante y Maipo. Los registros obtenidos corresponden al período de consolidación de la ocupación inca de la región y prueban que el Tawantinsuyu controló este sector de la cordillera para explotar una fuente de obsidiana y mantener en funcionamiento una red de tráfico especializado que vinculaba al valle central chileno con los valles orientales de Uco y Jaurúa. Por otra parte, las manifestaciones de arte rupestre halladas permiten inferir un proceso de sacralización y apropiación de este espacio dominado por el volcán Maipo y la laguna del Diamante.

Palabras clave: arqueología, control inca, ambientes de altura, frontera meridional del Tawantinsuyu.

\begin{abstract}
This paper presents the results of constructive techniques, space occupation patterns, chronology, lithic technology, ceramic technology and typology, camelid zooarchaeology, anthracology and studies of rock art from a group of archaeological sites in the Laguna del Diamante Natural Protected Area (Mendoza, Argentina). This area is located in the Cordillera Principal of the Andes and connects the upper Diamante and Maipo River Basins. Chronologically, the archaeological data are from the consolidation of the Inca occupation in the region. The studies demonstrate that the Inca state controlled this sector of the Andes in order to exploit an obsidian source and maintain a specialized trade network that linked the Central Valley in Chile with the eastern valleys of Uco and Jaurúa. Additionally, the rock art motifs allow us to infer a process of sacralization and appropriation of this landscape, which is dominated by the Maipo Volcano and the Diamante Lake.
\end{abstract}

Keywords: archaeology, Inca control, high altitude environments, Southern border of Tawantinsuyu.

Recibido: 18 julio 2020. Aceptado: 10 diciembre 2020 
El dominio incaico del valle central chileno y noroeste de la provincia de Mendoza, iniciado en las primeras décadas del siglo XV DC (Cornejo, 2014; Marsh, Kidd, Ogburn y Durán, 2017), generó cambios importantes en los modos de vida de las sociedades locales. Estudios históricos y arqueológicos muestran que, en ambas regiones vinculadas por la cordillera de los Andes, aumentó durante este período la producción agrícola mediante obras hidráulicas que permitieron un mejor manejo del agua (Michieli, 1994; Stehberg y Sotomayor, 2012), y posiblemente también la ganadera (Durán, Gasco, Paiva, Zonana y Barberena, 2020). Se hicieron explotaciones mineras de oro, plata y cobre (Cornejo, Miranda y Saavedra, 1999; Stehberg y Sotomayor, 2012) y mejoró sensiblemente la capacidad de transportar bienes e información a través de un sistema vial complejo (Stehberg, 1995; Bárcena, 1998). Para mantener el control sobre las sociedades locales, el Estado inca no solo utilizó la fuerza, sino que impuso también nuevas formas de organización social y creencias religiosas (Sánchez, 2004), destacándose el culto a los cerros o apus que incluyó, en ocasiones, sacrificios humanos (Schobinger, 2001).

En lo referido al límite meridional de la expansión incaica, para la vertiente occidental de la cordillera de los Andes existe consenso acerca de que el control estatal directo/efectivo (político y económico) llegó hasta el río Maipo/Cachapoal, con una frontera fluctuante entre estos ríos y el Maule, que perduró hasta la conquista hispana (Silva, 1985; Stehberg, 1995). Para la vertiente oriental, en cambio, se mantienen dos posiciones diferentes. Una considera que el control efectivo de los incas solo llegó hasta el río Mendoza, fundamentándose en la ausencia de arquitectura y obras viales de origen incaico al sur de este río (Hyslop, 1984; Bárcena, 1992; Cahiza y Ots, 2005; Ots, 2009). Para explicar la presencia de otros restos materiales de clara filiación incaica en los valles de Uco y Jaurúa (cuenca pedemontana del río Tunuyán), se ha propuesto que los incas explotaron estos espacios a través de enclaves o colonias que tenían propósitos económicos específicos (Bárcena 1992; Cahiza y Ots 2005; Ots 2009). En contraposición, García (2011) asume que los incas mantuvieron un control económico y político de esos valles, que puede percibirse en la cultura material (la cerámica específicamente) y en las formas de organización sociopolítica de las sociedades que describen las fuentes históricas del primer siglo de contacto hispano-indígena.

Al considerar más sólida la propuesta de García (2011), e incorporando los resultados arqueológicos publicados para las cuencas altas de los ríos Aconcagua, Mapocho y Maipo (Stehberg, 1995; Cornejo, Saavedra y Vera, 2006; Cornejo, 2008; Cornejo y Sanhueza, 2011a; Stehberg y Sotomayor, 2012; Pavlovic et al., 2019), se plantea aquí como hipótesis de trabajo que el Estado inca estableció un control directo de la franja oriental cordillerana comprendida entre los ríos Mendoza y Diamante, con el propósito de mantener en funcionamiento vías de comunicación trans e intercordilleranas y sus redes de intercambio vinculadas, como también para aprovechar ambientes de cordillera ricos en recursos (vegetales, animales y minerales) que solo podían obtenerse en el estío por condicionantes climáticos. Para contrastar esta hipótesis se desarrolló un proyecto de investigación centrado en la cuenca alta septentrional del río Diamante. Se presentan en este trabajo resultados de distintas líneas de estudio (técnicas constructivas y patrón de ocupación del espacio, cronología, tecnología lítica, tipología y tecnología cerámica, zooarqueología de camélidos, antracología y arte rupestre) desarrolladas en el Área Natural Protegida Laguna del Diamante. También se hace una revisión de los resultados alcanzados en la región por otros proyectos de investigación, con el objeto de discutir modelos de poblamiento vigentes que, por su rigidez, han obstaculizado la búsqueda de explicaciones alternativas para los registros del Período Inca obtenidos en lugares donde no se esperaba encontrarlos. 


\section{Descripción geográfica del área}

El Área Natural Protegida Laguna del Diamante (en adelante, ANPLD) está emplazada sobre una caldera volcánica de forma elíptica de $(20 \times 16 \mathrm{~km})$ ubicada en la cordillera del Límite (Sruoga, Etcheverría, Folguera, Repol y Zanettini, 2004) (Figura 1). Las cotas bajas del interior de la caldera $(<3300 \mathrm{msnm}$ ) han sido ocupadas, en su mayor parte, por la laguna del Diamante y otros cuerpos de agua dulce menores. El agua de derretimiento de las crestas montañosas que rodean la laguna discurre hacia ella a través de arroyos y por infiltración dentro de las coladas volcánicas que se extienden desde el cono del volcán Maipo hacia el este y sudeste. Del extremo meridional de la laguna nace el río homónimo que en su curso inicial fluye sobre un valle con poca pendiente hasta vencer la pared sur de la caldera.

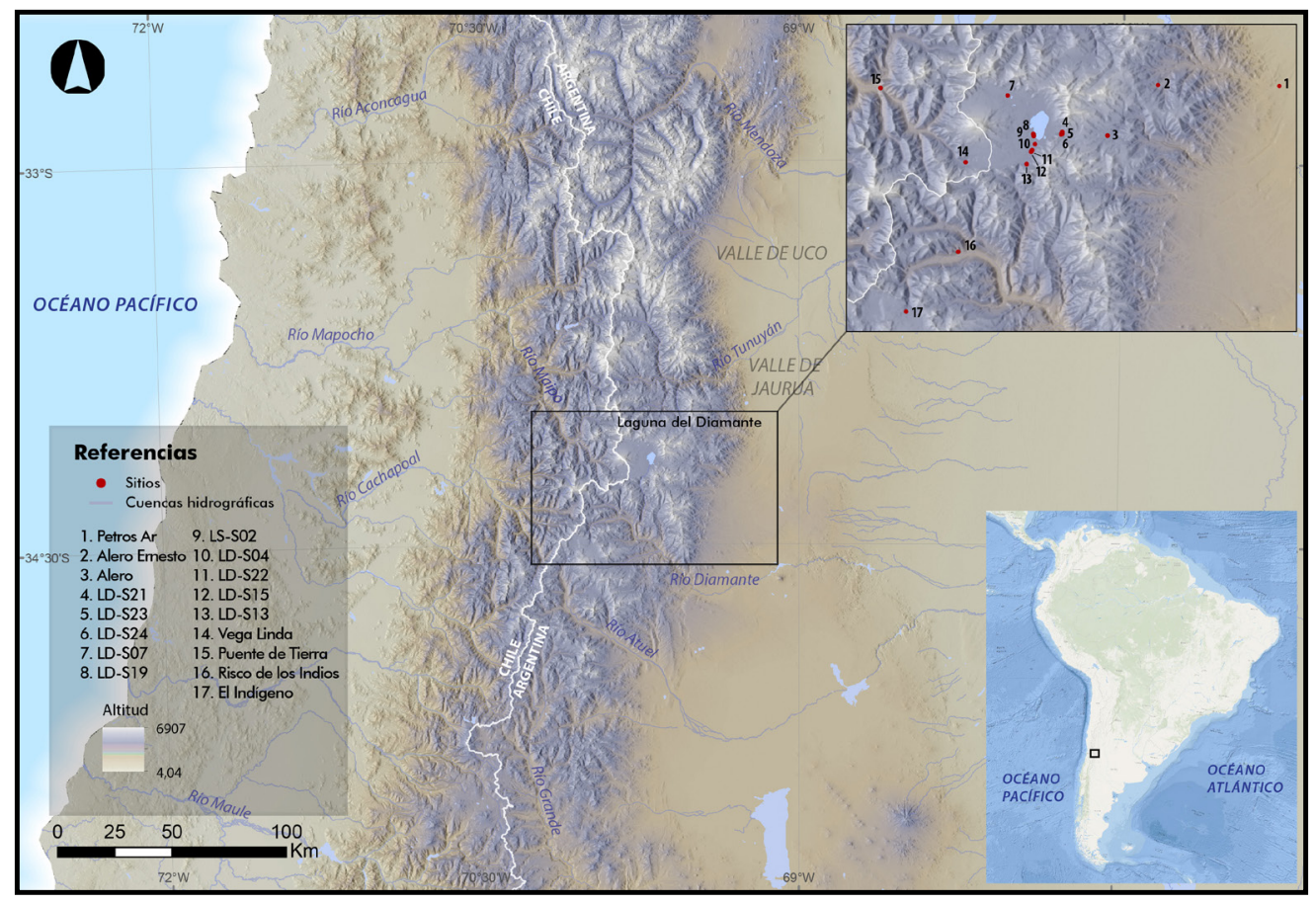

Figura 1. Mapa de la macrorregión.

En las superficies planas libres de agua domina una estepa arbustiva baja y muy abierta, en donde se destacan elementos altoandinos y patagónicos (Dalmasso, Martínez Carretero, Videla y De Lugan, Dalmaso et al., 1996). Extensas zonas con saturación de agua permiten el crecimiento de vegas o humedales. Dentro de los ambientes de cordillera, las vegas son los ecosistemas con mayor productividad (Scotti, Durán y Lecitra, 2012). Eso hace que sean aprovechadas estacionalmente por distintas clases de herbívoros (especialmente Lama guanicoe) y sus depredadores. Vegas, estepas, lagunas y cursos de agua, en los que se concentra una gran cantidad de aves, ocupan una parte importante de las cotas bajas de Caldera del Diamante. Por ello, en la estación cálida, la oferta de recursos bióticos de estos ambientes es elevada, relativamente constante y, en consecuencia, predecible (Figura 2). 
En cuanto a los recursos abióticos, el área ofrece agua dulce en abundancia y con una distribución amplia. Hay disponibilidad de rocas silíceas y de dos variedades de obsidiana (Cortegoso, Barberena, Durán y Lucero, 2016; Durán et al., 2018; Cortegoso et al., 2020). También se han localizado manifestaciones de material cuprífero diseminado y óxidos de hierro y arcillas (Durán, Neme, Gil y Cortegoso, 2006).

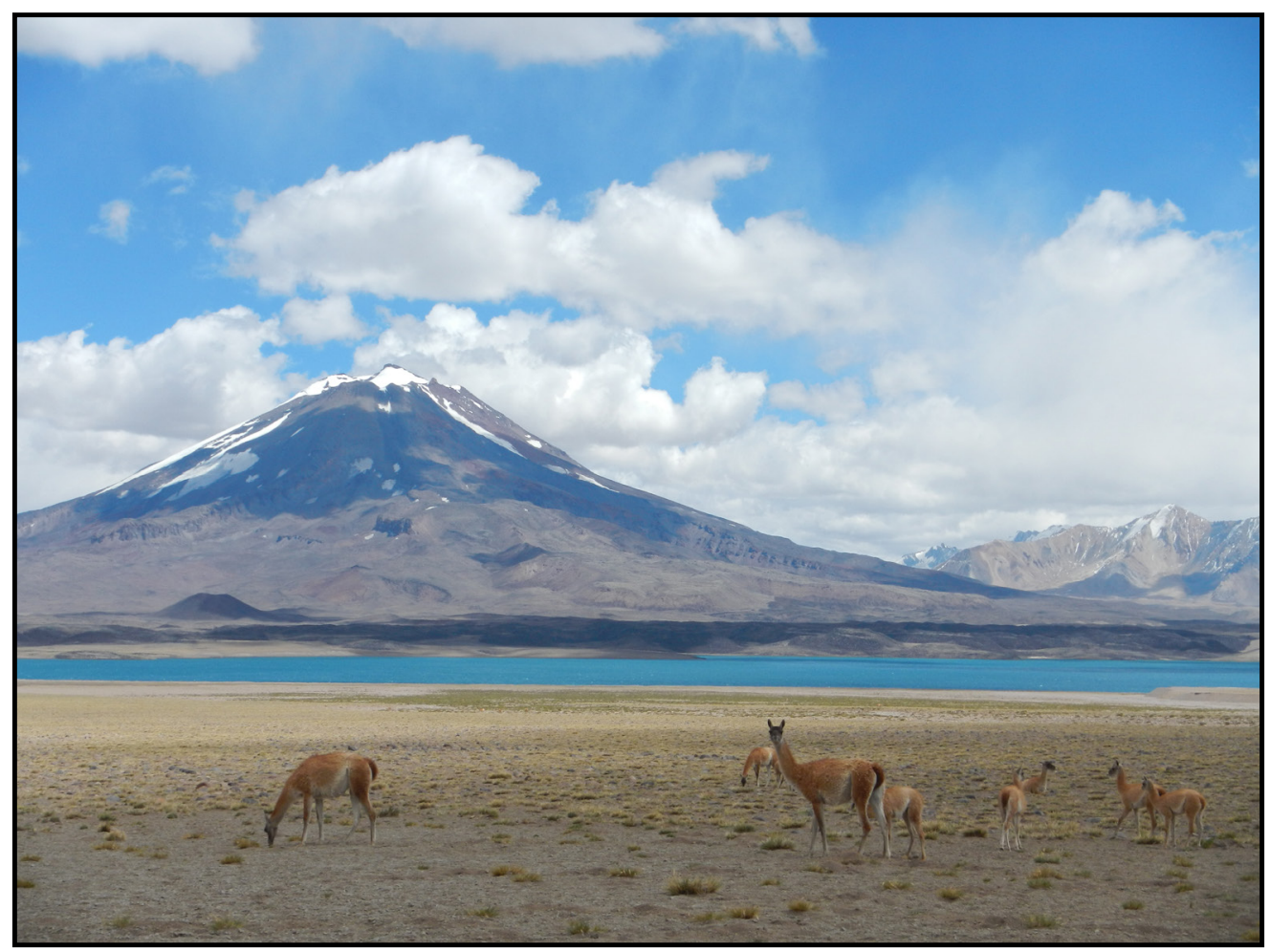

Figura 2. Fotografía de la laguna del Diamante y del volcán Maipo.

Las condiciones ambientales son favorables para su ocupación estacional y es el clima ${ }^{1}$ la limitación más importante para su uso humano. Las vías de acceso también son factores limitantes, pero no todas presentan igual grado de dificultad. Para ingresar desde el oeste solo es necesario atravesar el portezuelo del Maipo, ubicado a $3470 \mathrm{msnm}$. A través del mismo, ANPLD se vincula al Cajón del Maipo y por este último al valle central chileno. Ingresar desde el este es, en cambio, una tarea más compleja que obliga a cruzar por valles muy encajonados como el del río Diamante o portezuelos emplazados por encima de los $3700 \mathrm{msnm}$.

\section{Antecedentes}

En los últimos 20 años, las cuencas cordilleranas altas de los ríos Maipo y Diamante han sido intensamente estudiadas por distintos equipos de investigación (Lagiglia, 1999; Durán et al.,

1 La temperatura media anual es en la laguna de $2{ }^{\circ} \mathrm{C}$ y el promedio de precipitaciones, $600 \mathrm{~mm}$, con un régimen invernal. De acuerdo con la clasificación de Koeppen, es un clima polar ETH - de tundra con alta heliofanía- (Dalmasso et al., 1996). 
2006; Neme, 2007; Cornejo, 2008). La cuenca del Maipo es la que tiene los registros más antiguos, con fechas comprendidas entre los ańos 6000 y 4000 AP (Cornejo y Sanhueza, 2011a y b). Dado que los sitios con ocupaciones de cazadores-recolectores se encuentran a no más de $25 \mathrm{~km}$ de la Caldera del Diamante o en sus límites, se entiende que grupos de cazadoresrecolectores debieron transitarla o aprovechar sus recursos durante ese período y posterior. Todavía esta presunción no ha podido contrastarse, ya que los registros arqueológicos obtenidos en las cotas más bajas de la Caldera $(<3300 \mathrm{msnm})$ se inician con fechas próximas a los 2100 años AP y mantienen características que perduran hasta el Período Inca. Se trata de sitios con estructuras circulares pircadas que aparecen en agrupaciones variables (de algunas unidades a varias decenas) y se ubican próximos a fuentes de agua y vegas. Sus registros incluyen elementos de molienda, artefactos líticos confeccionados, en general, sobre obsidiana y fragmentos de cerámica con frecuencias predominantes de tipos propios de los períodos Alfarero Temprano (PAT), Intermedio Tardío (PIT) y Tardío (PT) de la periodización del valle central chileno (Durán et al., 2006, 2018).

Para explicar la existencia de este tipo de sitios, ampliamente distribuidos en la región, están vigentes tres propuestas, dos de las cuales tienen una clara base etnohistórica. ${ }^{2}$ La primera fue publicada por Lagiglia (1999) -siguiendo a Madrid (1977) - y la mantuvo Neme posteriormente (2007, 2016; Neme et al., 2016). Ambos autores entienden que estos ambientes de altura fueron ocupados casi exclusivamente por cazadores-recolectores de las planicies orientales. Neme considera que su ocupación se dio tardíamente (segunda mitad del Holoceno Tardío) como consecuencia de un proceso de intensificación iniciado por crecimiento demográfico en los ambientes más bajos de la vertiente oriental. Este proceso habría llevado a aquellos cazadores-recolectores orientales a hacer uso de ambientes altos que no habían sido atractivos, hasta entonces, por presentar una oferta menor e incierta de recursos (Neme, 2007, 2016; Morgan et al., 2017).

La segunda propuesta tiene por autores a Cornejo y Sanhueza (2011a y b), quienes también retoman lo expuesto por Madrid (1977) y consideran que en el valle del Maipo se dio, desde alrededor del año $2000 \mathrm{AP}$ hasta la llegada de los españoles, una coexistencia de cazadoresrecolectores y agricultores, correspondiéndoles a los primeros el control de las tierras altas de la cuenca del Maipo y de los valles intercordilleranos orientales. Difieren del modelo anterior al entender que estos cazadores-recolectores eran dos sociedades distintas: una que provenía de las planicies orientales ubicadas entre los ríos Diamante y Atuel y otra que permanecía en los ambientes cordilleranos occidentales intermedios durante las estaciones frías.

El tercer modelo propone, para los últimos 2000 años, un uso recurrente de la cuencas altas de los ríos Diamante y Maipo por sociedades con economías agropastoriles provenientes del oeste -valle del Maipo y valle central de Chile-, ${ }^{3}$ sin negar la posibilidad de que hayan sido ambientes compartidos con cazadores-recolectores orientales (Durán et al., 2006, 2018; Barberena et al., 2019; Andreoni y Durán, 2021).

2 Madrid (1977) y Lagiglia (1999) utilizan la descripción de Bibar (siglo XVI DC) sobre los puelches -cazadores recolectores orientales- y sus actividades de intercambio con agricultores occidentales para inferir que eran ellos, específicamente los chiquillames, los que ocupaban las cuencas cordilleranas altas de los ríos Maipo y Diamante.

3 La posibilidad de ocupaciones estacionales de agricultores occidentales había sido considerada para el sitio El Indígeno por Falabella y Sanhueza (Falabella, Sanhueza, Neme y Lagiglia, 2001; Sanhueza et al., 2004), pero la abandonan posteriormente (Falabella et al., 2016). 
El Período Inca, en las cuencas cordilleranas de los ríos Maipo, Diamante y Tunuyán, cuenta con una cantidad destacable de registros arqueológicos. La primera es la que manifiesta mayor densidad y diversidad, seguramente motivada por su proximidad al centro administrativo mayor o capital provincial que los incas establecieron entre los ríos Mapocho y Maipo (Stehberg y Sotomayor, 2012) y que aprovecharon los españoles posteriormente para fundar la ciudad de Santiago. En la cuenca cordillerana del Maipo se han encontrado sitios arqueológicos vinculados a vías de comunicación transcordilleranas (Cornejo et al., 2006), explotación minera (Cornejo et al., 1999), ceremonias religiosas en montañas (Ibacache y Cantarutti, 2003) y también prácticas funerarias (Cornejo, 2008). Para el sitio más meridional, Puente de Tierra, se ha propuesto que tuvo la función de marcar el límite de la expansión del Estado (Cornejo, 2008). Este sitio incluye dos estructuras pircadas, rectilíneas, con muros dobles orientados siguiendo los puntos cardinales, un bloque con un petroglifo serpentiforme y un topu. En las proximidades de estos, además, se ubicaron alrededor de una decena de recintos circulares y un alero. Si bien Cornejo menciona que pudo haber un interés del Estado inca por controlar el paso del Maipo (distante unos $30 \mathrm{~km}$ ) y los recursos que por allí fluían, considera que el sitio funcionó como un demarcador del límite de la expansión estatal. En un trabajo posterior, Cornejo y Sanhueza (2011a) profundizan esta propuesta al concluir que este paso perdió durante el Período Inca el protagonismo que había tenido hasta entonces, y que los espacios que estaban fuera del límite establecido por el Estado (en Puente de Tierra específicamente) se mantuvieron bajo el control de cazadores-recolectores cordilleranos. En esos espacios se encuentra la mayor densidad de sitios de la cuenca alta del Maipo, los cuales se destacan por presentar estructuras pircadas adosadas a grandes bloques y cerámica inca en sus superficies y estratigrafías.

En la cuenca cordillerana alta del río Diamante, fuera de ANPLD, se encuentran dos sitios con registros que pueden atribuirse al Período Inca: Risco de Los Indios (Neme et al., 2016; Morgan et al., 2017; Sugrañes, 2019) y El Indígeno (Lagiglia, 1999; Neme, 2007). El primero se ubica aproximadamente a $20 \mathrm{~km}$ al sur-sureste del Paso del Maipo y a menor distancia de los pasos del río Bayo y de La Cruz de Piedra, que conducen al valle del río Maipo y al sitio Puente de Tierra. Lo conforman un conjunto de 19 recintos circulares, en los que fueron registradas cerámicas de estilos Diaguita inca y/o Inca local del valle central chileno. Esta asignación tipológica se basa en la observación de fotografías de fragmentos cerámicos considerados de estilo Aconcagua en el trabajo de Morgan y colaboradores (2017, p. 219, Fig. 5B, D y F). También se incluyen en este contexto vegetales domesticados (Phaseolus sp.), una estructura amojonada demarcatoria (tipo topu o apacheta) y tres fechas radiocarbónicas correspondientes al Período Inca (se analizan posteriormente). Varios autores sostienen que este conjunto de recintos fue la base residencial de un grupo de cazadores-recolectores con alta movilidad y que obtenían parte de su cerámica y vegetales domesticados a través de intercambio (Neme et al., 2016, 2020; Morgan et al., 2017; Sugrañes, 2019). Por su parte, El Indígeno está ubicado por encima de los 3400 msnm y tiene 136 estructuras pircadas y registros similares a los descriptos para ANPLD, asignados también a cazadores-recolectores de las planicies orientales (Lagiglia, 1999; Neme, 2016). Se ha propuesto que su ocupación se inicia alrededor del año 1500 AP y termina en el 800 AP (Neme, 2016; Morgan et al., 2017). Con referencia a esta última fecha, resulta necesario destacar que estos autores no tuvieron en cuenta registros de cerámica Diaguita inca y posiblemente otras del mismo período, que aparecen en las recolecciones de superficie y que describe Lagiglia (1999).

Aproximadamente $25 \mathrm{~km}$ al noroeste de la laguna del Diamante, se ubica la localidad arqueológica Arroyo Campos Borbarán (Bárcena, 2003, 2010), situada en la cuenca alta meridional del río Tunuyán. Comprende dos refugios naturales ubicados a $2800 \mathrm{msnm}$, en un depósito de 
ignimbritas con petroglifos distribuidos a lo largo de varias decenas de metros. Uno de los aleros (Alero Ernesto) tiene un contexto estratificado con cerámica de tipología incaica (Diaguita inca e Inca local de la vertiente oriental-Viluco) y una fecha radiocarbónica correspondiente al Período Inca (se analiza posteriormente). Esta localidad está ubicada en un nodo de sendas pre y poshispánicas que permiten acceder desde el valle de Jaurúa al del Maipo. A pesar de las características de este registro y de su contexto, Bárcena $(2003,2010)$ lo asocia a puelches, huarpes o pehuenches (sociedades locales de la vertiente oriental).

Es claro que el modelo de poblamiento de base etnohistórica ha influido en la interpretación de los registros arqueológicos del Período Inca de la región. Pero este modelo se afirma en un supuesto erróneo que lo debilita. La documentación histórica seńala que los chiquillames (cazadores-recolectores orientales) se establecieron en la franja pedemontana de la cuenca del río Diamante recién a principios del siglo XVIII, por imposición de los espańoles (Prieto, 1989). Antes su territorio estaba en la Planicie Oriental, al sur de los ríos Diamante y Atuel (Durán, 2000). No hay información en la documentación histórica que permita ubicarlos en las cuencas altas de los ríos Diamante y Maipo durante el período inicial de contacto hispanoindígena.

\section{Registros arqueológicos del Período Inca en ANPLD}

\section{Características de los sitios}

En ANPLD se han localizado diez sitios arqueológicos que pueden asociarse al Período Inca (ver Figura 1), cuatro de ellos con recintos pircados (LD-S2, LD-S4, LD-S13 y LD-S21), cinco con petroglifos (LD-S7C, LD-S15, LD-S19, LD-S22 y LD-S23) y una cantera de obsidiana (LD-S24). Los cuatro sitios con recintos, caracterizados en este punto, tienen material en superficie y estratificado asignables al período indicado a partir de criterios tipológicos; dos de ellos cuentan con fechados radiocarbónicos que lo corroboran (LD-S4 y LD-S13).

LD -S2 incluye 29 recintos de planta circular con diámetros de tres metros promedio (Figura 3A). Se ubica a más de $250 \mathrm{~m}$ de la costa occidental de la laguna del Diamante, en el extremo de una colada volcánica. Los muros de los recintos se han construido superponiendo, en forma irregular, bloques extraídos de la colada. Presentan distintas condiciones de conservación y alturas variables. Las alturas de los que han sido refuncionalizados, en su último período de ocupación o recientemente, superan en algunos casos el metro, mientras que otros solo están definidos por una línea de rocas. Se realizaron excavaciones de $1 \mathrm{~m}^{2}$ en tres recintos, siguiendo niveles artificiales de $5 \mathrm{~cm}$ hasta alcanzar profundidades próximas a los $20 \mathrm{~cm}$. Cuatro fechados radiocarbónicos (tres sobre carbón y uno sobre hueso) arrojaron edades comprendidas entre 2100 y 1400 ańos AP - uno de los fechados de 1400 años AP corresponde a un esqueleto humano localizado en la estructura 6- (Yebra et al., 2021). Aunque no se cuenta con fechados absolutos, por las características tipológicas del registro cerámico, se asignó al Período Inca el primer nivel por debajo de la superficie de las estructuras 1 y 3 (Durán et al., 2006, 2018; Yebra et al., 2021). En superficie, tanto en el interior de las estructuras como en el espacio abierto que se define hacia el este, se distribuyen molinos planos, moletas, productos de talla y artefactos líticos formatizados, mayoritariamente de obsidiana, y fragmentos cerámicos. Entre estos últimos también aparecen tipos asignables al Período Inca, en especial en las proximidades de la estructura 7, la de mayor tamaño (Figura 3A). 
LD-S4 está conformado por cuatro estructuras pircadas, tres recintos de planta circular/irregular y una estructura cuadrangular que encierra un espacio relativamente plano (Figura 3B). Se ubica sobre la margen izquierda del río Diamante, en el extremo de una colada volcánica y a $120 \mathrm{~m}$ de la llanura de inundación del río y de las vegas que allí se desarrollan. Se excavó en uno de los recintos una superficie próxima a los $3 \mathrm{~m}^{2}$, alcanzándose una profundidad de 55 $\mathrm{cm}-11$ extracciones de $5 \mathrm{~cm}-$. La secuencia se inicia con una fecha de alrededor de 1100 años AP y termina con registros del siglo XX (Durán et al., 2006, 2018; Yebra et al., 2021). En la extracción 5 (cuadrícula B) se obtuvo una fecha radiocarbónica de $490 \pm 40$ ańos AP (Yebra et al., 2021). Al tener en cuenta este fechado y otras características del registro, puede proponerse que este sitio fue abandonado después de la ocupación incaica y que recién volvió a ocuparse a principios del siglo XX, produciéndose como consecuencia de esta nueva instalación el desplazamiento vertical de material moderno. Se ha agrupado por ello dentro del Período Inca el material procedente de las extracciones 2 a 5 .

LD-S13 incluye una cavidad natural situada entre dos grandes bloques rocosos. Dos recintos pircados adosados a dichos bloques, uno circular y otro de planta irregular (Figura 3C). El sitio se ubica a $50 \mathrm{~m}$ de la margen izquierda del río Diamante, en una zona con un amplio desarrollo de vegas. Los trabajos arqueológicos incluyeron tres sondeos de 0,50 por $0,50 \mathrm{~m}$ : uno en el recinto circular (sondeo 1) y dos en el interior de la cueva (sondeos 2 y 3). Los sedimentos se retiraron siguiendo niveles artificiales de $5 \mathrm{~cm}$; en el sondeo 1 se extrajeron nueve niveles y doce en los sondeos 2 y 3 . Se obtuvieron fechados radiocarbónicos que ubican la ocupación inicial del sitio (tanto en la cueva como en el exterior) alrededor de 1500 AP (Durán et al., 2018). A esta ocupación inicial corresponden dos entierros humanos. Estudios isotópicos realizados sobre huesos y dientes de estos dos individuos permiten asignar su procedencia a la vertiente occidental y definir que uno de ellos tuvo una dieta rica en maíz en su infancia (Durán et al., 2018; Barberena et al., 2019). Una fecha radiocarbónica de $420 \pm 40$ años AP (Yebra et al., 2021), obtenida sobre carbón vegetal del nivel 5 del sondeo 1, permitió generar para este sondeo un componente que reúne los niveles 2 a 5 y se asocia al Período Inca.

LD-S21 está conformado por 11 recintos pircados: tres de forma circular o semicircular, tres de planta rectilínea yuxtapuestos y seis irregulares adosados a bloques (Figura 3D). Incluye además un área despedrada de alrededor de $200 \mathrm{~m}^{2}$. Desde esta plataforma se observa en plenitud el volcán Maipo y la confluencia de los arroyos Paramillos y de Las Vacas, que se ubica a $100 \mathrm{~m}$ al oeste. Los recintos se ubican en una zona con una oferta importante de agua y de recursos vegetales. En 2020, se realizó una excavación de $1 \mathrm{~m}^{2}$ en el recinto 6 y una

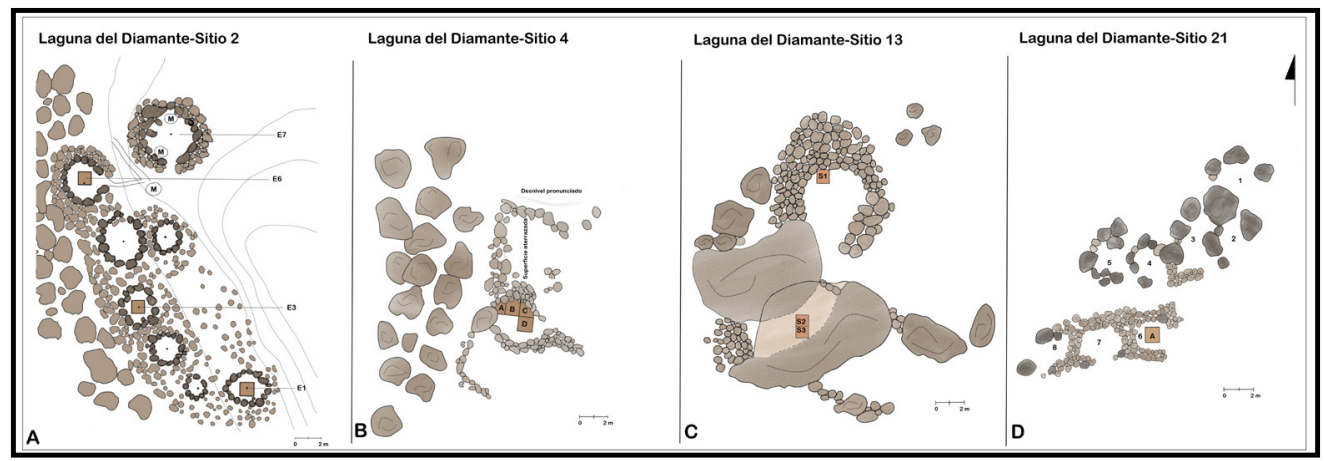

Figura 3. Planimetrías de sitios con componente inca y recintos pircados. 
recolección sistemática de material superficial sobre un área de $300 \mathrm{~m}^{2}$. Dentro del material cerámico recuperado aparecen tipos propios del Período Inca. Por otra parte, este sitio cobra una importancia particular por estar emplazado a alrededor de $600 \mathrm{~m}$ de una cantera de obsidiana y tener una clara vinculación con ella.

\section{Análisis espacial SIG}

Este análisis integra múltiples caminos de menor costo (LCP, Least Cost Paths) para predecir conectividad geográfica en paisajes topográficamente heterogéneos. A través de un DTM (Digital Terrain Model), se generaron maquetas del terreno con las posibles vías de circulación y los costos de desplazamiento entre sitios. Fueron objetivos específicos de este trabajo: a) modelar la conectividad de todos los sitios con asociación inca (de cualquier tipo) y la posible existencia de una red de corredores; y b) evaluar el grado de conectividad del paso Maipo y discutir la relevancia de ANPLD en la red de corredores establecida.

Se utilizó información georreferenciada obtenida en terreno e insumos ALOS-PALSAR de la fuente Alaska Satellite Facility. Los datos fueron procesados mediante SIG con los programas Q-Gis, ArcGis y Linkage Mapper (Núñez et al., 2013; Lucero, Castro, Marsh y Cortegoso, 2016). Se empleó el algoritmo de Tobler Off-Path modificado para calcular movimientos humanos en ambientes de altura (Lucero et al., 2016). De acuerdo a este modelo y a información etnográfica procedente de ambientes andinos comparables, los desplazamientos se miden en jornadas con rangos de 15 a $20 \mathrm{~km}$ de distancia (Nielsen, 2006; Yacobaccio, 2012). Los costos de desplazamiento se evaluaron a partir de la información resultante de la superficie de fricción y se aplicó, además, un modelo generado para ambientes de altura que pondera los movimientos en función de jornadas (Lucero et al., 2016).

A partir de la ubicación de sitios con registros del Período Inca, se modelaron corredores que siguen cuencas fluviales y sectores de menor resistencia. Los análisis de múltiples LCP muestran que se da una alta conectividad entre todos los sitios, dentro de ANPLD y en su periferia. Existen dos corredores de alta conectividad y varios de menor jerarquía que vinculan la cuenca cordillerana alta del río Maipo, a través de las cuencas cordilleranas altas de los ríos Diamante y Tunuyán con el Piedemonte Oriental (Figura 4). Por otra parte, el análisis LCP señala a ANPLD como un área con una alta conectividad, ya que es allí donde muchos flujos convergen. Dado que esta zona presenta la mayor biomasa asociada a la subsistencia, podría considerársela como un nodo de conectividad (sensu Nielsen, 1997). En ANPLD la conexión de las dos vertientes cordilleranas se produce a través de varios pasos (Alvarado, Maipo, Río Bayo y Cruz de Piedra), siendo el del Maipo el de mayor amplitud y menor altura (Figura 4). En la Tabla 1, se han incorporado los valores obtenidos y promediados desde LD-S2/19 hacia los otros sitios, para demostrar la importancia de ANPLD en la articulación de espacios entre vertientes y su conectividad y transitabilidad.

Los caminos delineados son producto de un modelo que traza rutas óptimas de menor costo en función de la topografía. En este tipo de modelo no se tienen en cuenta aspectos sociales o simbólicos de la conducta humana. Esto implica que las rutas trazadas pudieron no ser necesariamente la única alternativa, por ejemplo, la conectividad entre el sitio LD-S13 y Risco de los Indios se proyecta por el río Bayo y no por el río Diamante que parecería ser la ruta más viable. 
Tabla 1. Transitabilidad y conectividad entre sitios desde LD-S2/19.

\begin{tabular}{|c|c|c|c|c|c|}
\hline Hacia & Distancia Km & Horas & Jornadas 10 hs & $\mathbf{K m} / \mathbf{h}$ & Conectividad \\
\hline LD-S4 & 2 & 0.98 & 0.1 & 2 & Alta \\
\hline LD-S22 & 3 & 1.73 & 0.2 & 1.6 & Alta \\
\hline LD-S15 & 3 & 1.93 & 0.2 & 1.6 & Alta \\
\hline LD-S13 & 6 & 3.17 & 0.3 & 1.9 & Alta \\
\hline LD-S21 & 6 & 3.62 & 0.4 & 1.7 & Alta \\
\hline LD-S23 & 6 & 3.93 & 0.4 & 1.6 & Alta \\
\hline LD-S24 & 6 & 4.17 & 0.4 & 1.4 & Alta \\
\hline LD-S7 & 10 & 5.72 & 0.6 & 1.7 & Alta \\
\hline Vega Linda & 15 & 9.00 & 0.9 & 1.6 & Alta \\
\hline Alero & 16 & 9.97 & 1.0 & 1.6 & Alta \\
\hline A. Ernesto & 30 & 20.67 & 2.1 & 1.5 & Alta \\
\hline Puente de Tierra & 38 & 22.83 & 2.3 & 1.7 & Alta \\
\hline $\begin{array}{l}\text { Risco de Los } \\
\text { Indios }\end{array}$ & 33 & 23.17 & 2.3 & 1.4 & Alta \\
\hline El Indígeno A & 51 & 36.17 & 3.6 & 1.4 & Alta \\
\hline AR-Petros & 55 & 36.97 & 3.7 & 1.5 & Alta \\
\hline
\end{tabular}

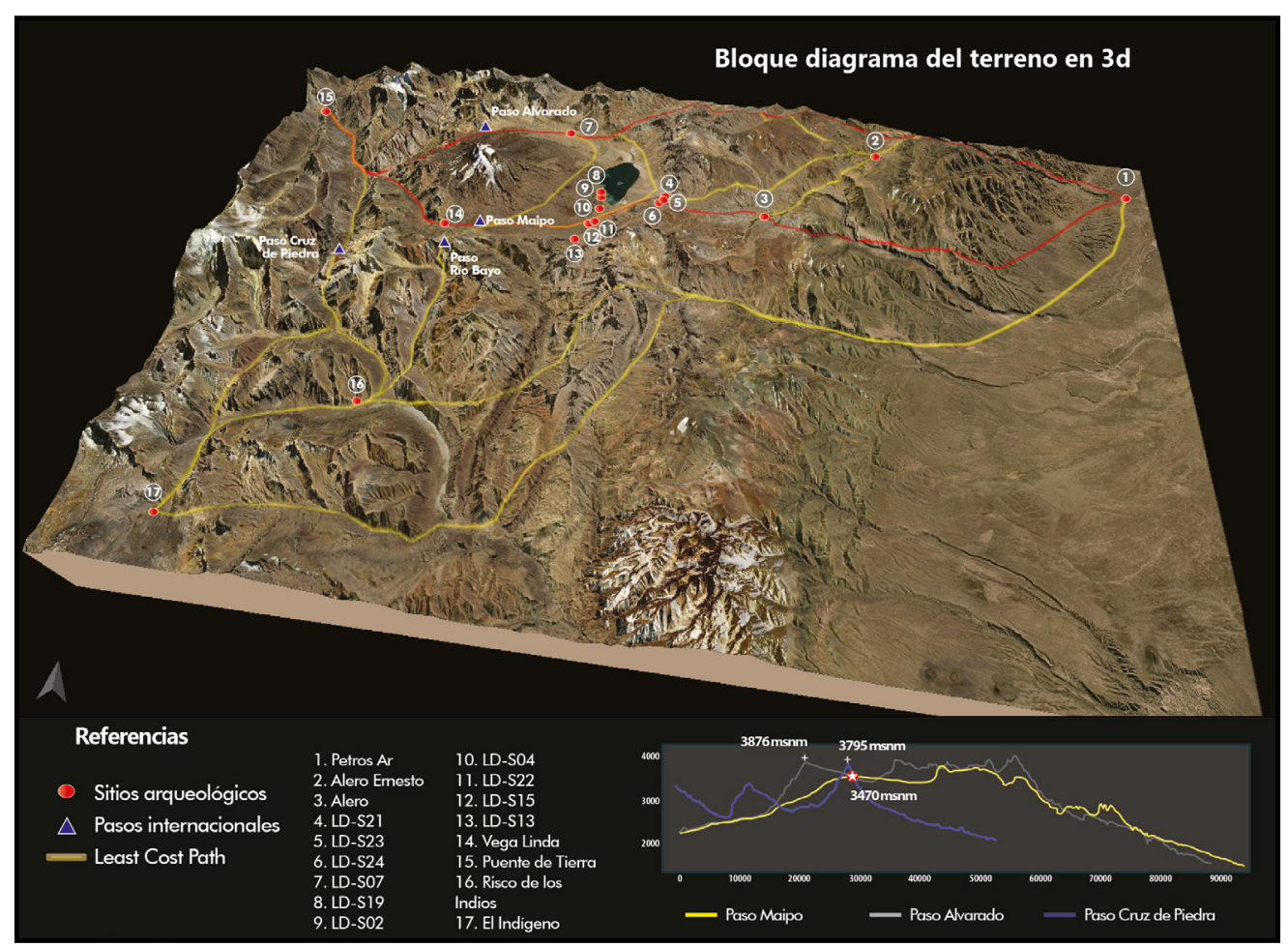

Figura 4. Corredores de conectividad. 


\section{Cronología}

Se calibraron y agruparon fechados radiocarbónicos de dos sitios de ANPLD, LD-S4 y LDS13 (Yebra et al., 2021), y de otros dos con registros contemporáneos y comparables, Alero Ernesto (Bárcena, 2010) y Risco de Los Indios (Morgan et al., 2017) (Tabla 2). Estos sitios se seleccionaron por su proximidad a ANPLD y por estimarse que formaban parte de la misma red de sendas de circulación.

Tabla 2. Fechados modelados.

\begin{tabular}{|c|c|c|c|c|c|c|c|c|}
\hline Sitio & Contexto & $\begin{array}{l}\text { Profundi- } \\
\text { dad } \\
(\mathrm{cm})\end{array}$ & $\begin{array}{l}\text { Código de } \\
\text { laborato- } \\
\text { rio }\end{array}$ & $\stackrel{\text { Edad }}{{ }^{14} \mathrm{C}}$ & \pm & $\begin{array}{l}\text { Mediana } \\
\text { calibra- } \\
\text { da (DC) }\end{array}$ & $\begin{array}{c}95 \% \text { rango } \\
\text { de } \\
\text { probabilidad }\end{array}$ & Material \\
\hline LD-S13 & $\begin{array}{l}\text { Sondeo } \\
\text { externo, } \\
\text { ext. } 5\end{array}$ & 25 & $\begin{array}{c}\text { LP- } \\
3539\end{array}$ & 420 & 40 & 1510 & $1440-1630$ & carbón \\
\hline LD-S4 & $\begin{array}{c}\text { Estructura } \\
1, \\
\text { cuadrícula } \\
\text { B, sector } \\
\text { NE-SE, } \\
\text { ext. } 5\end{array}$ & 25 & $\begin{array}{c}\text { LP- } \\
3658\end{array}$ & 490 & 40 & 1450 & $1400-1600$ & carbón \\
\hline $\begin{array}{l}\text { Alero } \\
\text { Ernesto }\end{array}$ & $\begin{array}{c}\text { Nivel } \\
\text { superior }\end{array}$ & & $\begin{array}{c}\text { Beta- } \\
162400\end{array}$ & 460 & 60 & 1480 & $1400-1630$ & carbón \\
\hline $\begin{array}{l}\text { Risco } \\
\text { de Los } \\
\text { Indios }\end{array}$ & $\begin{array}{c}\text { Estructura } \\
22 \text {, Estrato } \\
\text { III, Nivel } \\
10\end{array}$ & $75-90$ & $\begin{array}{c}\text { AA- } \\
102653\end{array}$ & 478 & 38 & 1450 & $1410-1620$ & $\begin{array}{l}\text { carbón } \\
\text { disperso }\end{array}$ \\
\hline $\begin{array}{l}\text { Risco } \\
\text { de Los } \\
\text { Indios }\end{array}$ & $\begin{array}{c}\text { Estructura } \\
22, \text { Estrato } \\
\text { III, Nivel } \\
\text { 7, lente de } \\
\text { carbón }\end{array}$ & 72 & $\begin{array}{c}\text { UGAMS- } \\
13578\end{array}$ & 500 & 20 & 1440 & $1420-1460$ & carbón \\
\hline $\begin{array}{l}\text { Risco } \\
\text { de Los } \\
\text { Indios }\end{array}$ & $\begin{array}{c}\text { Estructura, } \\
\text { 22, Estrato } \\
\text { II, Nivel } \\
6, \text { lente de } \\
\text { ceniza }\end{array}$ & 55 & $\begin{array}{c}\text { UGAMS- } \\
13579\end{array}$ & 480 & 20 & 1450 & $1420-1480$ & carbón \\
\hline
\end{tabular}

$\delta^{13} \mathrm{C}$ fue estimado en $-24 \pm 2 \%$ para las fechas de LD-S4 y LD-S13; para las demás, no se informó.

Los fechados radiocarbónicos se calibraron y modelaron con la curva actual del hemisferio sur, SHCal (Hogg et al., 2013) en OxCal 4.3 (Bronk Ramsey, 2009). Sus calibraciones tienen rangos de probabilidad superpuestas con medianas de un rango restringido de 1450-1500 ańos DC (ver Figura 3). Luego se refinó la cronología con un modelo bayesiano simple. Son supuestos de este modelo que las fechas corresponden a una sola fase y que las de Risco de Los Indios se depositaron en orden estratigráfico, según los detalles publicados de la estructura excavada (Morgan et al., 2017). El modelo tiene un índice de acuerdo alto (146) y estima que la fase se dio entre 1440 y 1460 ańos DC. Todas las fechas tienen medianas de 1450 DC y rangos de error reducidos de 5 a 10 ańos cada uno. Sin embargo, se toma en cuenta la posibilidad que 
las fechas reales de estos eventos no se acerquen tanto en el tiempo. Este acercamiento puede ser el efecto del supuesto de que todas las fechas pertenecen a la misma fase, en donde la mitad correspondiente a Risco de Los Indios cae dentro de un lapso muy acotado.

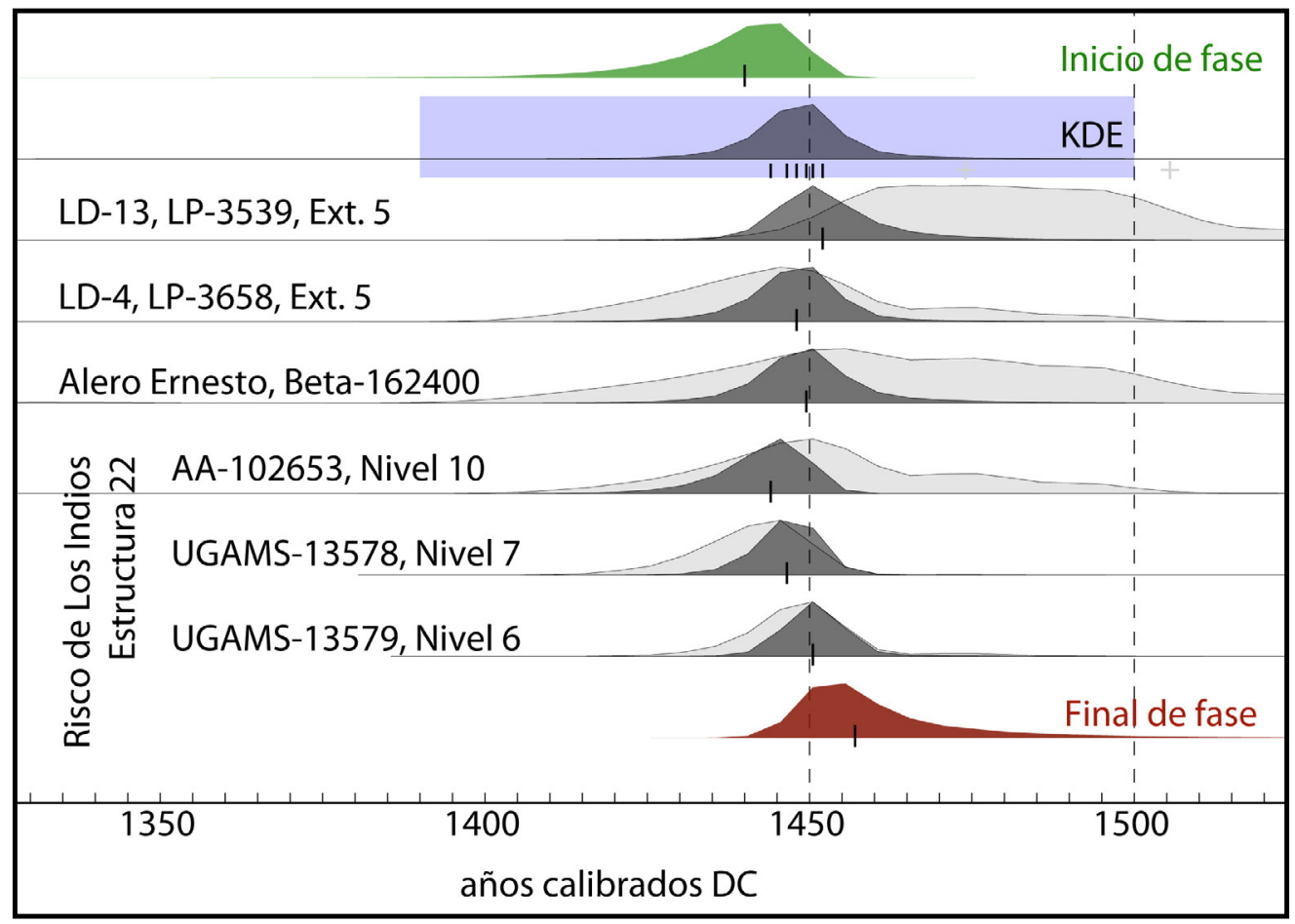

Figura 5. Rangos de probabilidad de los fechados de LD-S4, LD-S13, Alero Ernesto y Risco de los Indios. Las curvas en gris claro muestran las distribuciones de probabilidad calibradas, sin modelar. Las partes de las curvas de probabilidad menor de LP-3539 y Beta-162400, posterior a 1550 DC, se extienden fuera del gráfico. Las curvas en gris oscuro muestran las distribuciones de probabilidad luego de modelarse. Las líneas verticales bajo cada curva indican las medianas modeladas. La curva "KDE” (Kernel Density Estimate) es una síntesis de la densidad temporal de las seis fechas dentro de la fase (Bronk Ramsey, 2017).

Si se consideran los rangos calibrados o modelados, el patrón de ocupaciones ocurre cerca del año $1450 \mathrm{DC}$ o en las décadas posteriores. Estas fechas tienen una correspondencia clara con la presencia incaica registrada para el norte de Mendoza (Marsh et al., 2017) y Chile central (Cornejo, 2014). Estudios recientes de las fechas de contextos incas de ambas regiones sugieren una presencia inicial del Imperio próxima al ańo 1400 DC o algo anterior. También sitúan la densidad más alta de fechados en Chile central durante el lapso comprendido entre los años 1450 y 1500 DC (Cornejo, 2014). Por lo expuesto, puede concluirse que las ocupaciones registradas en ANPLD corresponden al inicio del período de consolidación de la ocupación inca de Chile central.

\section{Tecnología lítica}

En esta sección se presenta un estudio de intensidad de ocupación a través de la cuantificación del volumen de lascas proximales, una discusión sobre los resultados del análisis químico de artefactos de obsidiana y una descripción breve de la cantera/taller ubicada en ANPLD. 
Intensidad de ocupación en el rango temporal 450-500 años cal. AP

Para realizar una estimación sobre la intensidad de ocupación, se analizó el registro lítico de los sitios LD-S2 (Estructura 1 y 3, Ext.1 y Superficie), LD-S4 (Cuad. A y B, Ext. 2 a 6 y Cuad. C, Ext. 2 a 5) y LD-S13 (Sondeo 1, Ext. 2 a 5) (ver Figura 3). Se cuantificó el volumen de lascas proximales, ya que los productos de talla que conservan el remanente de plataforma de percusión representan un golpe real practicado en la talla. De esta manera, el conteo de lascas con plataforma permite calcular el NMG (Número Mínimo de Golpes), que puede ser considerado como un indicador de intensidad de ocupación (Andrefsky, 1998). El NMG está representado en este caso por las lascas proximales, LP, e instrumentos confeccionados en lascas, IL (Hiscock, 2002). Se registró para el Período Inca un n de 252 LP e IL, cuya división por el volumen de metros cúbicos excavados $(0,6055)$ arroja un total de 416,18 LP e IL por metro cúbico. Este período registra el índice más elevado de LP e IL, duplicando el del anterior más alto (1200-1280 años cal. AP; $\mathrm{n}=203$ por $\mathrm{m}^{3}$ ) (Yebra et al. 2021) (Figura 6). Los resultados indican que la ocupación tardía del área habría registrado una intensidad sensiblemente superior a todas las anteriores. Esto podría ser consecuencia de estadías más largas o recurrentes y/o un mayor número de personas.

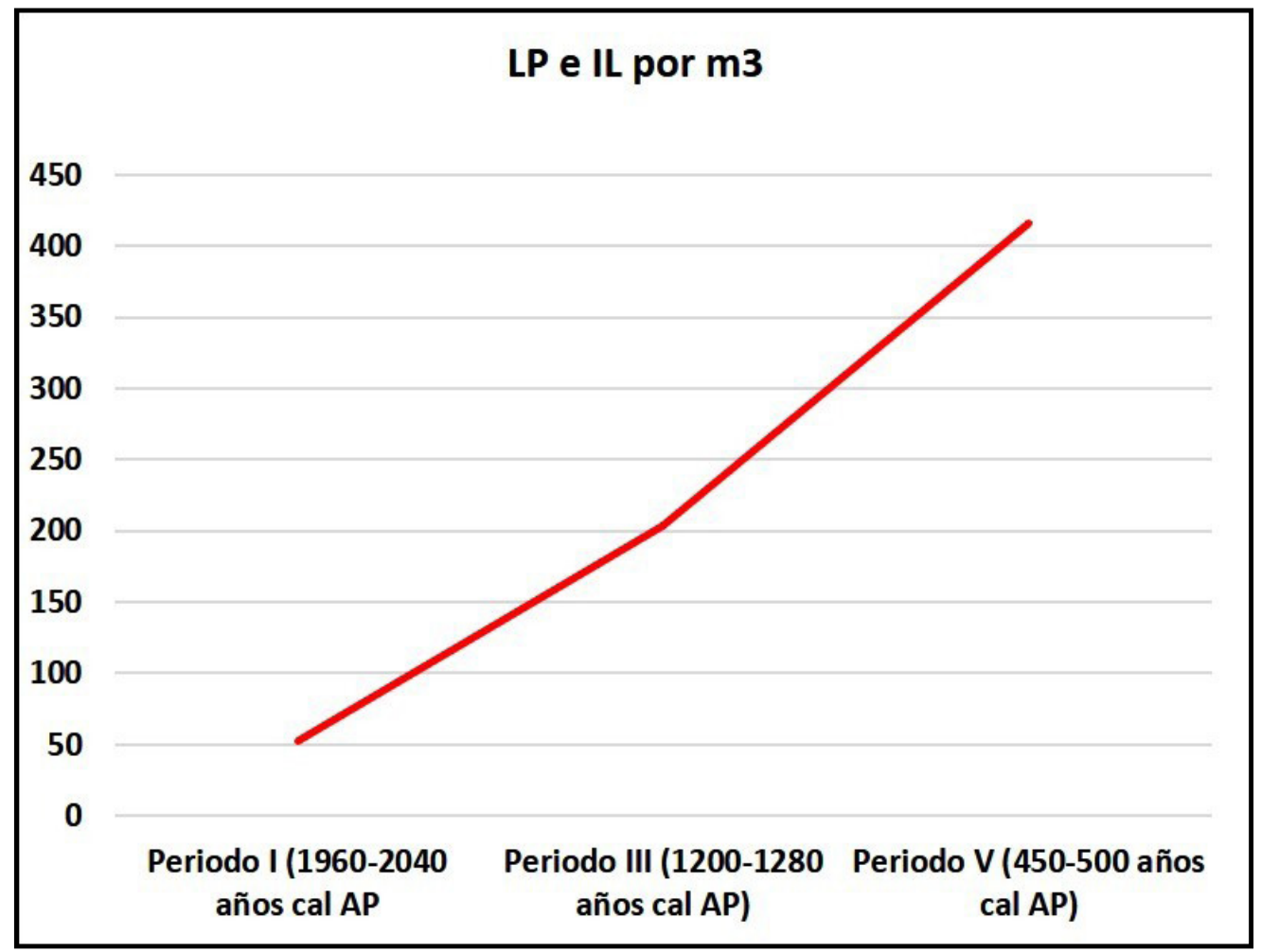

Figura 6. Índice de Lascas Proximales por Componentes temporales (fases de ocupación de ANPLD). 
Se aplicaron estudios geoquímicos mediante XRF (Cortegoso et al., 2020) a muestras de artefactos de obsidiana procedentes del registro asignado al Período Inca $(n=343)$. Los resultados muestran un uso mayoritario de las fuentes locales y la mayor diversidad de fuentes no locales de obsidiana en los cerca de dos mil años de ocupación de ANPLD. La fuente empleada de manera mayoritaria fue Laguna del Diamante $-64,43 \%-(n=221$, fuente local $)$, seguida por Arroyo Paramillos $-29,73 \%$ - ( $n=102$, fuente local), Las Cargas $-2,91 \%-(n=10)$, Laguna del Maule 1 y Cerro Huenul, ambas con $0,87 \%$ ( $n=3$ para cada fuente) y Laguna del Maule 2 y Desconocida B, ambas con $0,29 \%$ ( $n=1$ para cada fuente). Finalmente, hay artefactos de obsidiana que no han sido asignados a ninguna de las fuentes regionales, $0,58 \%(n=2)$.

La variabilidad de fuentes cordilleranas (LD, AP, LC, LM-1) y extracordilleranas (HU y LM-2) sugiere un cambio en relación a las ocupaciones previas. Desde ca. 1210 ańos cal. AP se registró la presencia de la fuente LC y Desconocida B. Las fuentes de obsidiana identificadas para el Período Inca indican desplazamientos de sur a norte que alcanzan, en línea recta, $300 \mathrm{~km}$ para HU, $290 \mathrm{~km}$ para LM-2, $220 \mathrm{~km}$ para LM-1 y $140 \mathrm{~km}$ para LC.

\section{Canteraltaller de obsidiana (LD-S24)}

En la ladera septentrional del cerro El Relincho, en un depósito morénico ubicado a 3700 msnm, se detectó un sector con disponibilidad natural de obsidiana concentrada en forma de nódulos con tamaños comprendidos entre 5 y $15 \mathrm{~cm}$ (Figura 7). Su dispersión a lo largo de $700 \mathrm{~m}$ sobre un talud de detritos alcanza a $3400 \mathrm{msnm}$ la margen izquierda de los arroyos de Las Vacas y Paramillos. La calidad para la talla de esta fuente de obsidiana es de muy buena a excelente. Sus características macroscópicas son similares a la obsidiana LD, que también se ha detectado y caracterizado por XRF en otro flanco del mismo cerro (Cortegoso et al., 2020). En la pendiente abundan nódulos y fragmentos con negativos de lascados de diversos tamańos. Por las evidencias de su explotación, LD-S24 puede ser considerado como una cantera/ taller (Nami, 1992). Pero resulta conveniente destacar que, dadas las condiciones naturales de fragilidad de la obsidiana y la dinámica del terreno, las evidencias de actividad de talla podrían estar sobrerrepresentadas debido a procesos tafonómicos.

Existe una clara vinculación entre esta cantera/taller y el sitio LD-S21 localizado a alrededor de $600 \mathrm{~m}$. Se registró allí un número importante de productos de talla y artefactos de obsidiana, tanto en superficie como en la excavación realizada. La presencia de percutores y productos de obsidiana en distintas etapas de la secuencia de talla son indicadores de su asociación a actividades de extracción y procesamiento de esa materia prima. Por otra parte, los dos sitios están relacionados con un bloque con grandes serpentiformes (LD-S23) que se ubica dentro de la misma cantera/taller (ver Figura 7). La asociación de estos serpentiformes a prácticas rituales incaicas, la presencia de cerámica inca en LD-S21 y su arquitectura similar a la del sitio Puente de Tierra (Cornejo, 2008) sugieren el interés de ese Estado por controlar la explotación de esta fuente de obsidiana. 


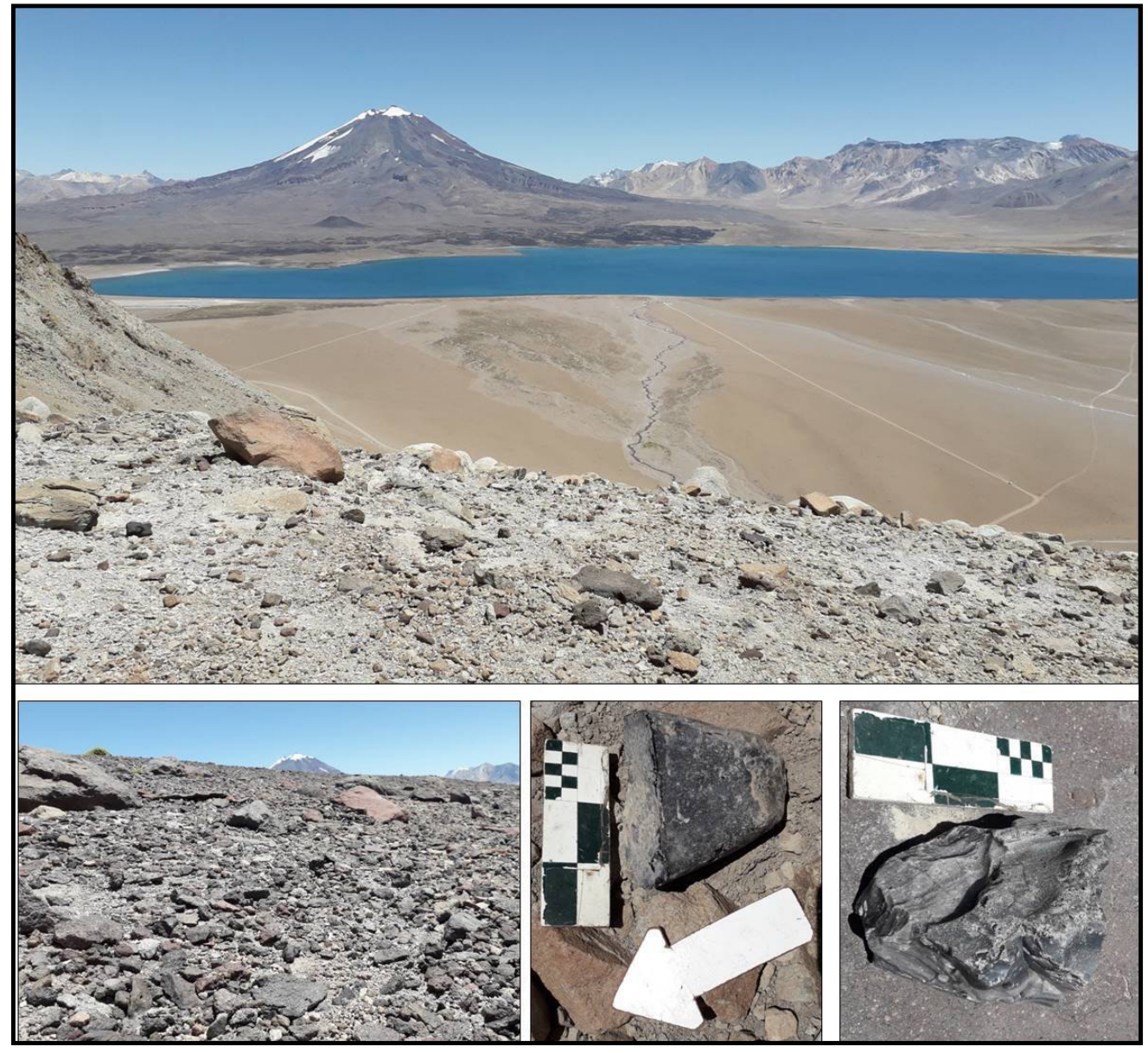

Figura 7. Sitio LD-S24, cantera/taller.

Arriba, laguna del Diamante y volcán Maipo vistos desde la cantera. Abajo, detalle de la cantera y ejemplos de nódulos hallados.

\section{Tecnología y tipología cerámica}

En esta sección se retoman trabajos previos que consistieron en clasificar en categorías de vasijas y tipologías los conjuntos cerámicos recuperados de los sitios LD-S2 y LD-S4 (Durán et al., 2006, 2018). Se actualizaron dichos resultados y se reagrupó la muestra en categorías de acuerdo a tratamientos de superficie y decoración; además se tuvieron en cuenta estados de atributos y rasgos técnicos considerados diagnósticos de tipos incaicos que pueden reconocerse en conjuntos fragmentados mediante observación macroscópica (Pavlovic, Troncoso, Sánchez y Pascual, 2012; Stehberg, Prado y Rivas, 2017). Con la finalidad de evaluar en términos relativos la cantidad de cerámica inca de los sitios de ANPLD, se estimaron frecuencias y densidades por categoría (Tabla 3) y se compararon los valores con densidades y frecuencias obtenidas para otros sitios incas de Chile central. 
Tabla 3. Frecuencias y densidades de materiales cerámicos del componente inca en los sitios LD-S2 y LD-S4.

\begin{tabular}{|c|c|c|c|c|c|c|}
\hline & \multicolumn{3}{|c|}{ LD-S4 } & \multicolumn{3}{c|}{ LD-S2 } \\
\hline $\begin{array}{c}\text { Tratamiento- } \\
\text { Decoración }\end{array}$ & $\begin{array}{c}\text { Frecuencia } \\
\text { absoluta }\end{array}$ & $\begin{array}{c}\text { Frecuencia } \\
\text { relativa }\end{array}$ & Densidad & $\begin{array}{c}\text { Frecuencia } \\
\text { absoluta }\end{array}$ & $\begin{array}{c}\text { Frecuencia } \\
\text { relativa }\end{array}$ & Densidad \\
\hline $\begin{array}{c}\text { Pintura roja } \\
\text { negro s/rojo } \\
\text { (Inca) }\end{array}$ & 19 & $18 \%$ & 0,0150 & 1 & $5 \%$ & 0,0100 \\
\hline Pintura roja & 15 & $14 \%$ & 0,0119 & 0 & $0 \%$ & 0,0000 \\
\hline Alisado-inciso & 2 & $2 \%$ & 0,0016 & 0 & $0 \%$ & 0,0000 \\
\hline Bruńido & 2 & $2 \%$ & 0,0016 & 0 & $0 \%$ & 0,0000 \\
\hline Pulido & 37 & $35 \%$ & 0,0293 & 8 & $38 \%$ & 0,0800 \\
\hline Alisado & 32 & $30 \%$ & 0,0253 & 12 & $57 \%$ & 0,1200 \\
\hline Total & $\mathbf{1 0 7}$ & $\mathbf{1 0 0} \%$ & $\mathbf{0 , 0 8 4 7}$ & $\mathbf{2 1}$ & $\mathbf{1 0 0 \%}$ & $\mathbf{0 , 2 1 0 0}$ \\
\hline
\end{tabular}

La muestra incluye el total de fragmentos cerámicos pertenecientes al Período Inca de los sitios LD-S4 ( $\mathrm{n}=107)$ y LD-S2 $(\mathrm{n}=21)$. El 35,1\% $(\mathrm{n}=45)$ corresponde a cerámica pulida y el 34,3\% a cerámica alisada $(n=44)$. Ambos grupos presentan pastas y superficies grises y marrones con distintas tonalidades. No poseen atributos diagnósticos que permitan asociarlos claramente a una tradición cerámica. A pesar de ello, cerámica que presenta estas características ha sido asignada en Risco de Los Indios a tipos alfareros locales de cazadores-recolectores orientales (Neme et al., 2016; Morgan et al., 2017; Sugrañes, 2019). Este tipo de asociaciones tipológicas debe realizarse con cautela, en especial para el caso de la cerámica Overo (Lagiglia, 1999), cuyos atributos externos y patrones de pasta (estilos tecnológicos) guardan estrechas similitudes con la cerámica Llolleo (Sanhueza, Falabella, Fonseca y Andonie, 2004). Atribuir a cazadoresrecolectores esta cerámica es discutible, dado que podría tratarse de cerámica de estilo/tradición Llolleo replicada a nivel local, o bien haber sido producida en la vertiente occidental y trasladada hacia las tierras altas cordilleranas. Trabajos recientes de mineralogía automatizada de pastas por QEMSCAN, Quantitative Evaluation of Minerals by Scaning Electron Microscopy (Frigolé et al., 2018), aplicados a materiales cerámicos del área de estudio, Chile central y norte semiárido, muestran similitudes en la composición mineralógica de Overo con Llolleo. Por otra parte, resultados de Análisis de Activación de Neutrones (Sugrañes, 2019), aplicados a muestras halladas en distintos ambientes de la cuenca del río Diamante y Atuel, evidencian que los tipos cordilleranos de la vertiente oriental (Overo y Nihuil) y los de la vertiente occidental (Llolleo, Aconcagua y posibles tipos Incas) poseen una composición química similar y conforman un mismo grupo que se diferencia de los de las tierras bajas de la vertiente oriental. Estos resultados sugieren una misma área de procedencia para todos los tipos mencionados, lo que apoya la propuesta del traslado de alfarería de los valles occidentales por sociedades que explotaban recursos de las tierras altas cordilleranas durante el verano (Durán et al., 2006, 2018).

Los fragmentos del conjunto clasificado como inca representan el 15,6\% ( $\mathrm{n}=20)$ del total de la muestra. Poseen superficies externas pintadas monocromas (rojo) y bicromas (negro sobre rojo) y pulidas. En las superficies internas presentan un tipo de escobillado (Figura 8) que no se halla en la cerámica de los contextos del PIT y es característico de la alfarería incaica en Chile central y norte semiárido chileno (Pavlovic et al., 2012; Stehberg et al., 2017; Cornejo y 
Saavedra, 2018). La densidad de dicho conjunto expresada según la razón fragmentos/litros es de 0,01 en el sitio LD-S2, y de 0,0150 en el sitio LD-S4. En términos generales, estos valores de densidad se encuentran dentro de los rangos estimados para fragmentos diagnósticos incas en contextos incaicos de Chile central, incluso podrían considerarse más altos que algunos de ellos (Cornejo y Saavedra, 2018: Tabla 2, p. 139).

La categoría de cerámica pintada roja representa el 11,7\% $(n=15)$. Incluye fragmentos que poseen superficies externas engobadas rojas y pulidas y podrían corresponder tanto a tipos Incas como Aconcagua (Durán et al., 2006, 2018).

Los conjuntos menos representados corresponden a cerámica de superficies externas bruñidas y pastas finas de color negro $(1,5 \%, \mathrm{n}=2)$ y gris incisa $(1,5 \%, \mathrm{n}=2)$. El primer tipo se asemeja a otros del norte semiárido chileno (Durán et al., 2006; Cornejo y Sanhueza, 2011b) y el segundo a tipos frecuentes en los períodos Temprano/Medio y Tardío del noroeste y centro-oeste de Mendoza (García, 2004). En la mayor parte de los sitios cordilleranos de la cuenca del Maipo aparecen tipos bruñidos en muy bajas frecuencias (Cornejo y Sanhueza, 2011b) y también en el área cordillerana y precordillerana del norte de Mendoza y sur de San Juan (Michieli y Gambier, 1998). Análisis de pastas por QEMSCAN asignan este tipo de cerámica a la vertiente occidental y la gris incisa, a la oriental (Frigolé et al., 2018).

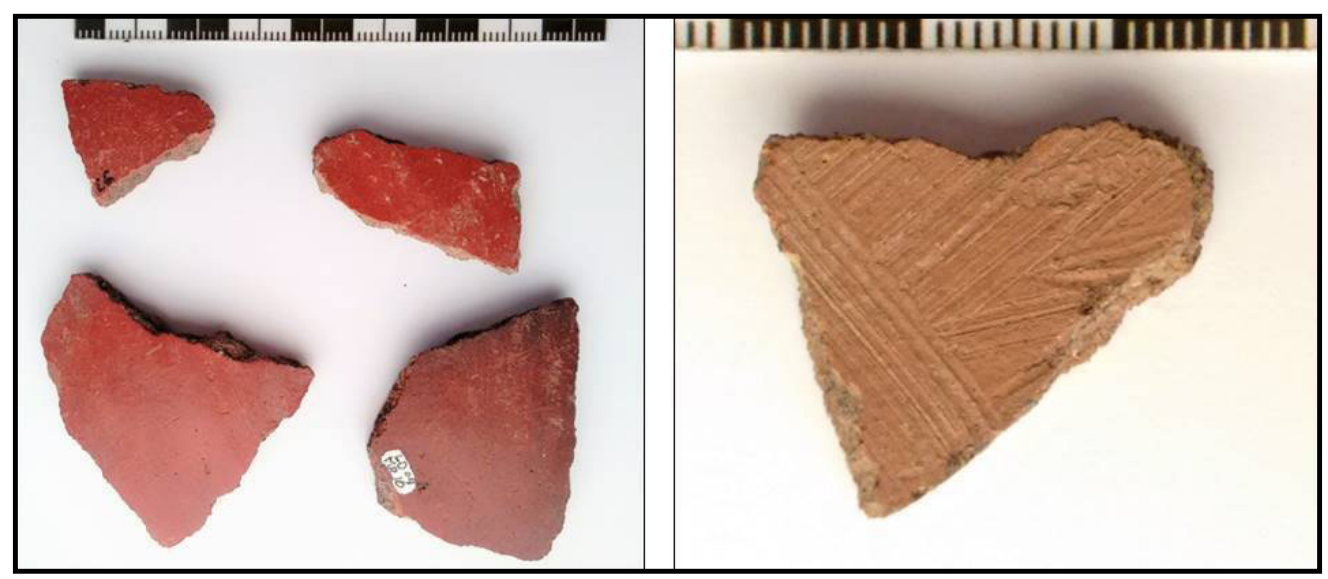

Figura 8. Superficies externas e internas de cerámica Inca en el sitio LD-S4.

\section{Zooarqueología: camélidos silvestres y domésticos}

Este estudio retomó el conjunto de Camelidae del registro arqueofaunístico del sitio LDS4. Los especímenes muestran una alta fragmentación producto de la meteorización. Solo el 4,3\% (NSP =15.202) pudo ser determinado a algún nivel taxonómico. En toda la secuencia de ocupación los camélidos predominan (más del 75\%), seguidos por aves de diferentes tamaños (7,7\%) y Dasipódidos (3,8\%) (Durán et al., 2006: Tabla 8). En los primeros están representados individuos neonatos, juveniles y adultos y no se registra selección de partes anatómicas, lo que podría indicar que ingresaron completos al sitio.

El análisis de las marcas de origen cultural permitió inferir un aprovechamiento intensivo de las presas, por medio de la cocción y para el consumo de médula ósea. En trabajos anteriores 
referidos a este conjunto arqueofaunístico (Durán et al., 2006; Neme et al., 2020) no se observó una tendencia clara que marcara cambios en el aprovechamiento de Camelidae a través del tiempo. No obstante, al reagrupar los datos, se advirtió un aumento de su presencia durante el Período Inca, en el que se aprecia un NISP de 107, mientras que en los dos períodos anteriores es de 79 y 69 (Durán et al., 2006). Si se suma a estos últimos los especímenes de Artiodactyla, esa tendencia se robustece (NISP $=115,89$ y 75 , respectivamente). A pesar del bajo tamańo de la muestra, es importante considerar esta tendencia, ya que resulta poco frecuente hallar en sitios de altura, a cielo abierto, registros faunísticos numerosos y con buenas condiciones de preservación.

También se aplicaron análisis osteométricos y estadística multivariada (análisis de componentes principales y análisis de conglomerados) sobre 12 especímenes que cumplieron los requisitos para la aplicación de técnicas métricas. Todos fueron comparados con la Colección de Referencia de Camélidos, con una base analítica comparativa más robusta (Gasco, 2014), y se los discriminó taxonómicamente. Nueve fueron identificados como Lama guanicoe y tres como Lama glama (ver detalles en Gasco, 2013), estos últimos corresponden al Período Inca.

Al tener en cuenta que es complejo diferenciar llama y guanaco a nivel osteológico (Yacobaccio y Vilá, 2013), se prefirió utilizar osteometría (Cartajena, Núnez y Grosjean, 2007; Izeta, 2009; Gasco, 2013, y citas en ellos), técnica que ofrece numerosas ventajas analíticas como la replicabilidad y la sencillez. Solo precisa una base de datos actual numerosa, representativa y controlada de cada especie de camélidos, que actúe como referencia comparativa (Gasco, 2014 y citas allí). Además, al no establecer grupos de tamaño/forma a priori y trabajar con los datos métricos crudos, las pruebas estadísticas que se aplican evidencian la variabilidad de las relaciones entre los datos arqueológicos y actuales, evitando sesgos en el análisis, lo que no sucede cuando se aplica anatomía comparada, ya que generalmente utiliza pocos esqueletos de referencia. Por otra parte, para la región de estudio, otros análisis arqueofaunísticos han partido de un sesgo actualístico, al aceptar que todo el registro identificado macroscópicamente como Camelidae pertenece a Lama guanicoe porque es la única especie de camélidos que vive actualmente en estos ambientes (Neme et al., 2020).

La presencia de animales domésticos identificada con una base metodológica fuerte invita a replantear hipótesis sobre estrategias de subsistencia y patrones de ocupación del espacio de las sociedades que habitaron ANPLD y disgrega en, al menos, dos especies la preponderancia de camélidos registrada en la secuencia de ocupación del sitio. En este contexto, se asume que la evidencia de especímenes de Lama glama da cuenta de la ganadería como estrategia combinada con la caza y del uso del área como un ámbito de pastoreo para rebaños, implicando una posible práctica de trashumancia (Gasco, 2013). Asimismo, abre el juego sobre su utilización como animales de carga en circuitos de intercambio.

\section{Antracología}

El conjunto antracológico analizado procede de los registros del Período Inca de LD-S2, LDS4 y LD-S13. La metodología de trabajo consistió en la comparación de los carbones arqueológicos con referencias de maderas actuales. Con anterioridad a la determinación, los carbones se pesaron, contabilizaron y se separaron en tres tamaños distintos (a-2-5 mm; b- 5 a $10 \mathrm{~mm}$ y c- > a $10 \mathrm{~mm}$ ) para evitar sesgar la muestra en favor de aquellos taxones que dejan carbones de mayor tamańo. La submuestra analizada se definió por medio de la construcción de una curva de riqueza específica (Andreoni y Capparelli, 2012). 
Para la identificación taxonómica se utilizó la colección de referencia de maderas del área de estudio (Andreoni, 2015; Andreoni y Durán, 2021) y descripciones anatómicas de maderas de Chile (Rancusi, Nishida y Nishida, 1987). Respecto del nivel de determinación, en algunos casos fue posible arribar a familia (p.e., Asteraceas), en otros se llegó a género (p.e.,Adesmia sp.) y en otros a nivel especie (p.e., Gomortega keule). En algunos casos, debido al solapamiento de rasgos anatómicos, fue imposible diferenciar entre dos géneros (p.e., Acacial Prosopis), mientras que otros se definieron como afines (aff.) a una especie (p.e., Acacia aff. caven). La categoría indeterminable incluye los carbones en los que no fue posible reconocer la estructura de la madera (Andreoni y Durán, 2021).

Se analizaron 179 carbones, de los cuales se identificó el 94,97\%. Se pudieron diferenciar 10 taxones vegetales distintos: Familia Asteracea, Acacia aff. caven, Gomortega keule, Austrocedrus chilensis, Persea lingue, Quillaja saponaria, Ochetophila trinervis, Prosopis aff. alpataco (raíz), Adesmia sp. y Acacial Prosopis (Tabla 4). En términos de frecuencia, Adesmia sp. fue la madera mayormente colectada para leña, representando el 75\%, que son junto con Ochetophila trinervis los dos únicos taxones identificados en los tres sitios. En términos de riqueza taxonómica, en LD-S4 se identificaron seis taxones, en LD-S13, siete y en LD-S2, dos.

Un aspecto relevante del registro antracológico es la presencia de maderas de distintos ambientes: pudieron diferenciarse maderas locales, como Adesmia sp. y Familia Asteraceae, y otras procedentes de pisos de vegetación más bajos de la vertiente occidental. Entre estos se incluyen Acacia aff. caven que actualmente crece en el Bosque Espinoso Mediterráneo y se distribuye en todo el valle central chileno y en el piedemonte occidental de la cordillera de los Andes. De este mismo piso procede, probablemente, Acacia sp./Prosopis sp. Mientras que en el Bosque Esclerófilo Andino, ubicado entre los 1400 y 2200 msnm, se debió colectar Austrocedrus chilensis, Persea lingue, Quillaja saponaria y probablemente Gomortega keule (Luebert y Pliscoff, 2017). Por otra parte, del piedemonte oriental de la cordillera Frontal se debió colectar Prosopis aff. alpataco, especie nativa de las provincias fitogeográficas de Monte y Patagónica. La procedencia de Ochetophila trinervis es más compleja de establecer, ya que esta especie crece tanto en la cuenca del río Maipo como en arroyos cordilleranos orientales.

El estudio del registro antracológico de los períodos previos en ANPLD también muestra que la recolección de maderas locales fue predominante (p.e., Adesmia sp.) y que se introducen, aunque en menor proporción, especies de pisos altitudinales inferiores (p.e., Ochetophila trinervis). Para estas primeras ocupaciones la riqueza taxonómica es baja identificándose solo cuatro taxones: dos locales -Adesmia sp. y Asteraceae- y dos foráneos -Quillaja saponaria y Ochetophila trinervis- (Andreoni y Durán, 2021). Esta tendencia en el uso de especies locales se mantiene durante el Período Inca y se incrementa la riqueza taxonómica de los conjuntos a nueve taxones. Se incluyen maderas de los valles de Chile central (p.e., Acacia aff. caven, Quillaja saponaria, Austrocedrus chilensis, entre otras) y otras del piedemonte oriental de la cordillera Frontal (p.e., Prosopis aff. alpataco), ausentes en las primeras ocupaciones del área. Esta ampliación en los rangos de aprovisionamiento de leña refleja el aprovechamiento de recursos de distintos pisos ecológicos y la existencia de una estrategia de aprovisionamiento previa al ascenso a las tierras altas. 
Tabla 4. Resultados antracológicos para ANPLD.

\begin{tabular}{|c|c|c|c|c|c|c|c|c|}
\hline \multirow{2}{*}{ Taxones } & \multicolumn{2}{|c|}{ LD-S2 } & \multicolumn{2}{|c|}{ LD-S4 } & \multicolumn{2}{|c|}{ LD-S13 } & \multicolumn{2}{|c|}{ Total ANPLD } \\
\hline & No & $\%$ & No & $\%$ & No & $\%$ & No & $\%$ \\
\hline Familia Asteraceae & - & - & 8 & 7,77 & - & - & 8 & 4,47 \\
\hline $\begin{array}{l}\text { Austrocedrus } \\
\text { chilensis }\end{array}$ & - & - & & 0,00 & 3 & 8,33 & 3 & 1,68 \\
\hline Gomortega keule & - & - & & 0,00 & 1 & 2,78 & 1 & 0,56 \\
\hline $\begin{array}{l}\text { Ochetophila } \\
\text { trinervis }\end{array}$ & 5 & 12,5 & 1 & 0,97 & 2 & 5,56 & 8 & 4,47 \\
\hline Persea lingue & - & - & 1 & 0,97 & - & - & 1 & 0,56 \\
\hline $\begin{array}{l}\text { Prosopis aff. } \\
\text { alpataco (raíz) }\end{array}$ & - & - & 3 & 2,91 & - & - & 3 & 1,68 \\
\hline Quillaja saponaria & - & - & 3 & 2,91 & 1 & 2,78 & 4 & 2,23 \\
\hline $\begin{array}{l}\text { Acacia sp./ } \\
\text { Prosopis sp. }\end{array}$ & - & - & - & - & 2 & 5,56 & 2 & 1,12 \\
\hline Adesmia sp. & 34 & 85 & 79 & 76,70 & 23 & 63,89 & 136 & 75,98 \\
\hline Indeterminables & 1 & 2,5 & 6 & 5,83 & 2 & 5,56 & 9 & 5,03 \\
\hline & 40 & - & 103 & - & 36 & - & 179 & - \\
\hline
\end{tabular}

\section{Arte rupestre}

En ANPLD se descubrieron cinco sitios con arte rupestre, en cuatro de los cuales (LD-S15, LD-S19, LD-S22 y LD-S23) aparecen motivos serpentiformes de gran tamaño. Estos motivos han sido registrados en otras regiones del Tawantinsuyu y se los ha caracterizado como incas (Hernández Llosas, 2006; Cornejo, 2008; Cruz, 2015). Es preciso señalar que fue necesario diferenciarlos de las fulguritas, improntas que los rayos dejan en las rocas y que también están presentes en ANPLD. Las fulguritas son vidrios formados por el rápido calentamiento que genera el impacto de un rayo sobre roca, arena o suelo. A medida que pasa, esta energía derrite, vaporiza y reduce químicamente el material expuesto, lo que resulta en un rápido cambio físico, químico y/o morfológico (Jones et al., 2005). Es común que en la zona de impacto se forme un pequeño orificio desde donde la energía se transmite a través de la superficie de la roca (Pasek, Block y Pasek, 2012), también puede generarse una aureola de contacto o un halo con presencia de minerales de cuarzo o vidrio generado por las altas temperaturas que superan los $1700{ }^{\circ} \mathrm{C}$ (Elmi, Chen, Goldsby y Gieré, 2017).

La fulgurita identificada (Figura 9) comienza en un orificio de aproximadamente $3 \mathrm{~cm}$ de diámetro (con una pequeńa aureola alrededor compuesta presumiblemente por óxidos o vidrio de aproximadamente $2 \mathrm{~cm}$ de ancho) ubicado en el sector más alto del bloque, a partir del cual se desarrolla la impronta hacia abajo de manera vertical. Presenta una forma serpentiforme, con bordes angulosos y es cuasisimétrica a lo largo de su eje vertical. Su impronta es blanquecina y forma una cobertura continua e intensa que impide la identificación de los minerales afectados. Finalmente, hacia la parte basal del bloque va angostando progresivamente su traza, concluyendo casi en un punto en cercanía del suelo. 


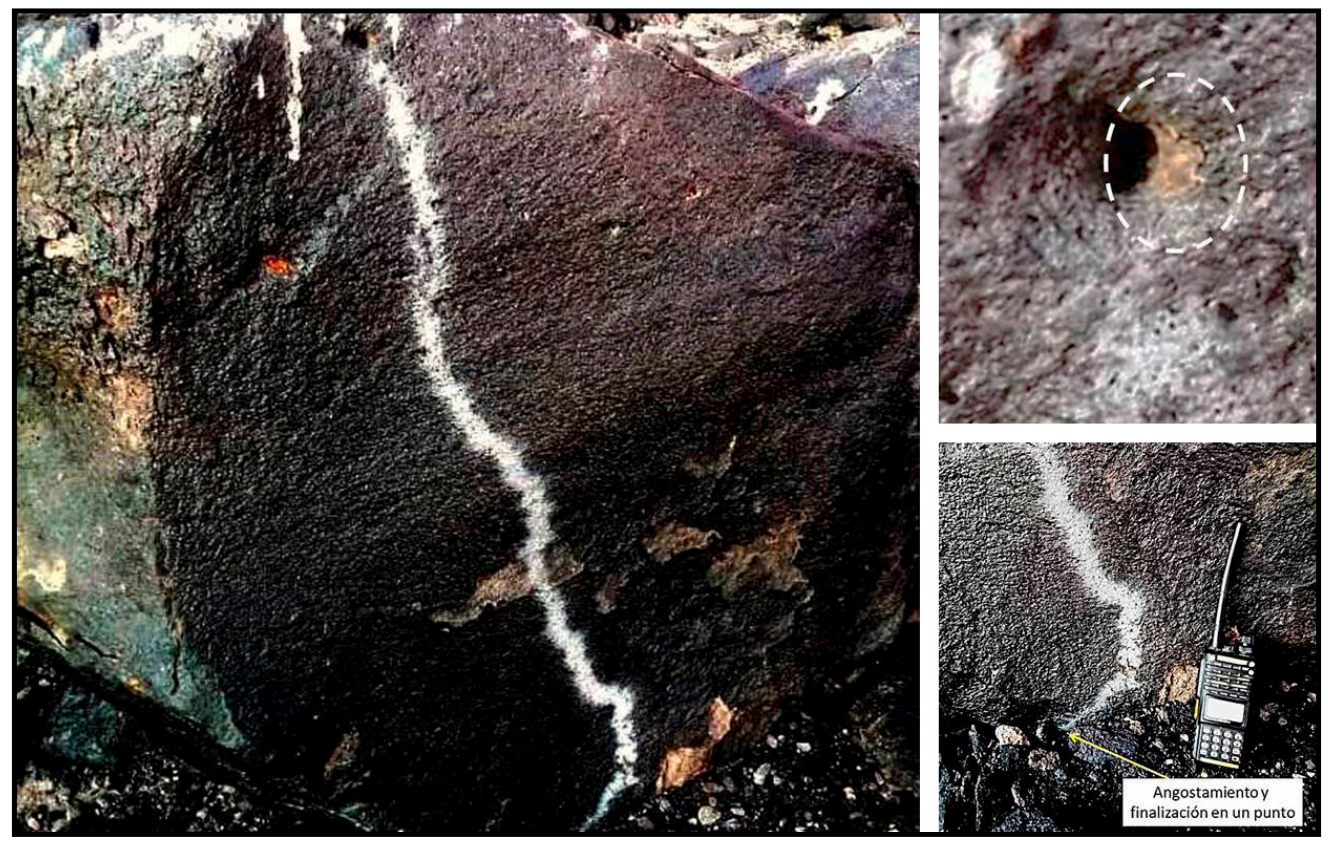

Figura 9. Fulgurita registrada en ANPLD.

A la derecha, detalles de orificio de impacto del rayo y del angostamiento y finalización en un punto. Fotografía: Gentileza del guardaparque Javier López.

A diferencia de la fulgurita, los motivos serpentiformes identificados en ANPLD tienen orientaciones disímiles, improntas más claras y en algunos casos se presentan acompañados por otros grabados. La técnica de ejecución varía de acuerdo a las características de superficie del panel: en los sectores donde es lisa y sin afectaciones se percibe un abradido suave, sin profundidad de surco, pero con marcado contraste con la coloración de la pátina; en los sectores donde la superficie del panel está meteorizada, se registran piqueteados que forman el surco. La técnica utilizada es particular, pues aunque se trata de abrasión, la sutileza de su ejecución hace que sea difícil de identificar. Para petroglifos similares se ha planteado su ejecución mediante termoalteración/rubificación (Cruz, 2015), aunque queda por experimentar otras opciones como abrasión con agua y arena o pumicitas.

$L D-S 15$ es un bloque de coloración oscura y aspecto suave, típico del barniz o pátina del desierto, que proviene de una colada del volcán Maipo de composición andesítica. Tiene adosada a su cara oriental una estructura parcialmente pircada, semicircular, de alrededor de $1 \mathrm{~m}^{2} \mathrm{y}$ contiene un único panel grabado que se orienta hacia el noreste, de $120 \mathrm{~cm}$ de altura y $70 \mathrm{~cm}$ de ancho (Figura 10). Se trata de una superficie plana vertical afectada por agrietamientos y meteorización en su extremo inferior. El serpentiforme se desarrolla de forma vertical y alcanza los $100 \mathrm{~cm}$ de largo, comienza en el extremo superior derecho y finaliza en el sector inferior medio; la impronta oscila entre los 3 y los $5 \mathrm{~cm}$ de ancho. Se observa piqueteado en el sector inferior, que coincide con la parte meteorizada de la roca. Se ubica a $130 \mathrm{~m}$ de una laguna menor y a $260 \mathrm{~m}$ al oeste de la margen derecha del río Diamante, sobre una meseta abierta que une el paso del Maipo con el valle del río mencionado.

$\boldsymbol{L D}$-S22 es una gran roca andesítica con un único panel grabado que se orienta hacia el noreste (Figura 10). Como en el caso anterior, se trata de una superficie plana vertical, pero 
con dimensiones mayores, ya que el panel alcanza $140 \mathrm{~cm}$ de alto por casi $170 \mathrm{~cm}$ de ancho. Presenta una pátina negra en la que resaltan dos serpentiformes que se yuxtaponen y que parecen formar una única figura altamente visible. El primero supera los $100 \mathrm{~cm}$ de largo y se desarrolla desde el extremo superior del panel hasta el sector izquierdo del mismo, mientras que el segundo recorre el panel desde el sector izquierdo hacia la parte inferior. Se registraron también dos figuras más pequeńas, una línea recta vertical de $27 \mathrm{~cm}$ y un tridígito de $20 \mathrm{~cm}$ en el sector superior del bloque donde se inicia el primer serpentiforme (existe una yuxtaposición parcial de las figuras, quedando el tridígito por debajo). Ambas figuras, la línea y el tridígito, fueron manufacturadas a partir de piqueteado lineal cuyo surco oscila entre los 7 y $10 \mathrm{~mm}$ de ancho. Este bloque se ubica a $70 \mathrm{~m}$ de la margen derecha del río Diamante y tiene una vinculación clara con LD-S15. Los dos bloques grabados parecen marcar un segmento de una senda, hoy inexistente, que debió unir el río Diamante con el paso del Maipo.
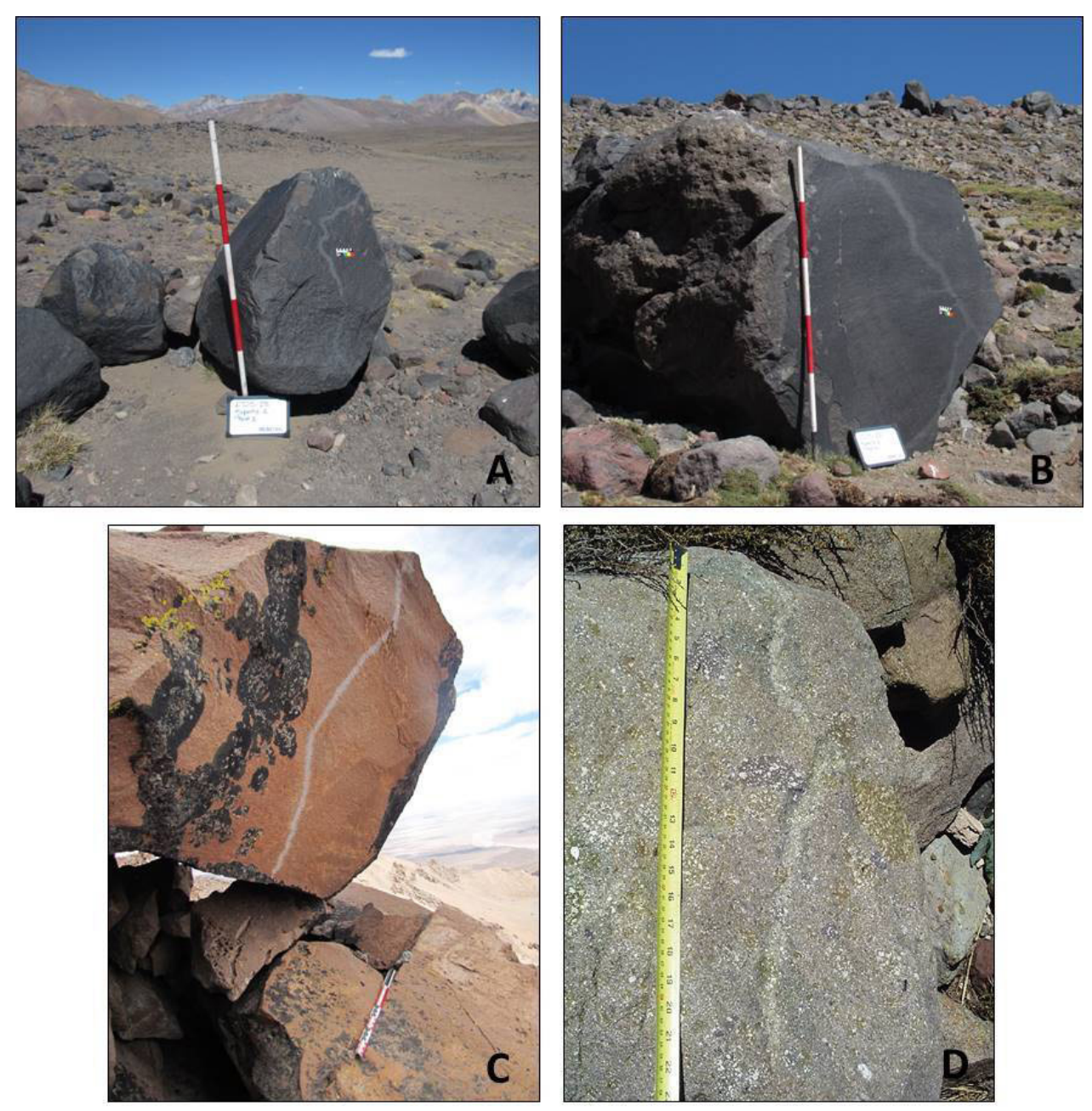

Figura 10. Serpentiformes de ANPLD y similares de otras regiones del Tawantinsuyu.

A y B) Petroglifos de LD-S15 y LD-S22, en ANPLD; C) Serpentiforme ubicado en la cumbre del cerro Cuzco (cordillera de los Frailes, Potosí, Bolivia), asociado con santuario de altura inca (Fotografía: Gentileza Pablo Cruz); D) Serpentiforme del sitio Puente de Tierra (Fotografía: Gentileza Luis Cornejo). 
LD-S19 es un bloque de andesita con varios sectores de su pátina meteorizados. Este proceso ha afectado incluso al panel grabado, de $80 \mathrm{~cm}$ de alto por $75 \mathrm{~cm}$ de ancho. Contiene un serpentiforme en el costado derecho del panel, de $60 \mathrm{~cm}$ de longitud, efectuado mediante abrasión. Es el serpentiforme menos notorio de ANPLD debido a su meteorización. Además, se registró un círculo pequeño realizado mediante piqueteado areal, con un diámetro de $5 \mathrm{~cm}$. Este bloque está ubicado a unos metros de una línea de costa pasada la laguna del Diamante y, aproximadamente, $70 \mathrm{~m}$ al norte del recinto más septentrional de LD-S2.

$\boldsymbol{L D}-\boldsymbol{S} 23$ es un bloque de una roca intrusiva, de coloración gris oscura y de textura microgranosa. Tiene un único panel vertical grabado de gran tamańo (sobrepasa los $2 \mathrm{~m}$ tanto de alto como de ancho), orientado hacia el sur-sureste. En la pátina rojiza resaltan dos serpentiformes horizontales que superan los $2 \mathrm{~m}$ de extensión y se desarrollan casi en paralelo (Figura 11). La figura superior es más visible, alcanza los $5 \mathrm{~cm}$ de ancho y se yuxtapone con la inferior (menos notoria debido a que su impronta promedia $1 \mathrm{~cm}$ de ancho) en el extremo derecho de ambas. Se ubica en la ladera norte del cerro Paramillos, a $400 \mathrm{~m}$ al sureste del sitio LD-S21, dentro del área de dispersión de material tallado de la cantera (LD-S24). Al emplazarse en el sector medio del cerro tiene un dominio visual de la mayor parte de la cantera, de la laguna del Diamante y de los arroyos de Las Vacas y Paramillos.

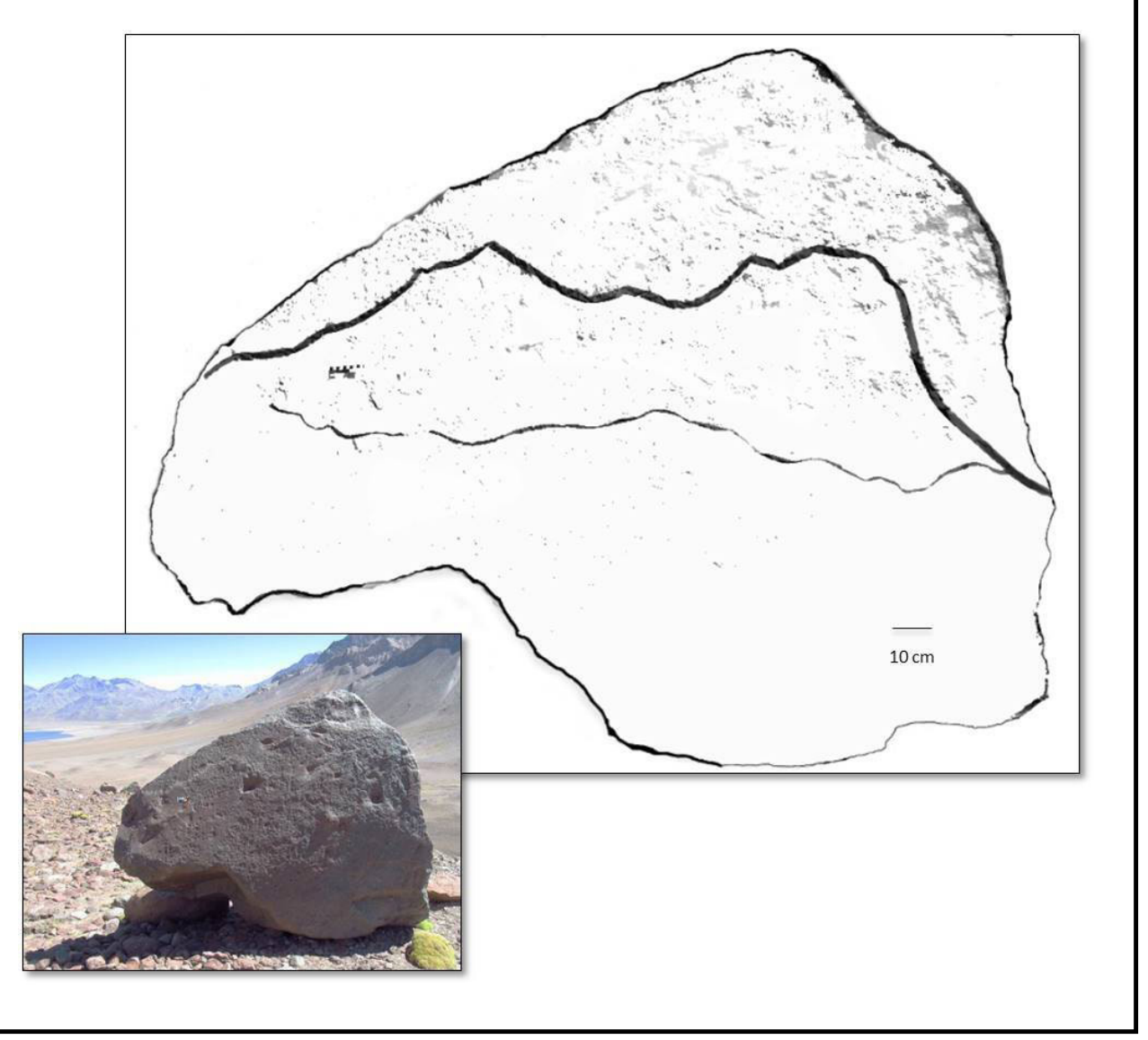

Figura 11. Petroglifo de LD-S23.

Calco obtenido mediante Adobe Photoshop. En la esquina inferior, fotografía original. 
Para hacer una propuesta sobre la adscripción cronocultural de las figuras serpentiformes y su funcionalidad, se consideraron los registros rupestres de una región distante y dos próximas. En el altiplano surandino boliviano (departamento de Potosí), Cruz (2015) identificó varios sitios con motivos serpentiformes, que presentan una llamativa semejanza con los de ANPLD, tanto en lo figurativo como en lo técnico. Cruz (2015) relaciona estas grafías con la imagen de Illapa, deidad asociada al rayo, y destaca su asociación con adoratorios incaicos de altura y/o establecimientos mineros del mismo período. En la cuenca cordillerana alta del río Mendoza, a más de 3000 msnm, se ubica el sitio Portezuelo Colorado, donde varios serpentiformes más pequeños que los de ANPLD están en asociación directa con figuras vinculadas a los incas: cruz inscrita, motivos cuatripartitos y fitomorfos semejantes a la planta de maíz (Zárate Bernardi, Puerto y Marsh, 2020). El emplazamiento del sitio permite postular que su funcionalidad se relacionaría a marcación de rutas de movilidad intracordillerana y al acceso a espacios sacralizados (al cerro Aconcagua, específicamente). Por su parte, en la cuenca cordillerana alta del río Maipo, Cornejo (2008) registra un serpentiforme en el sitio Puente de Tierra. La presencia de este motivo a ambos lados de la cordillera y prácticamente en la misma latitud permite asumir que estas grafías podrían estar marcando rutas de movilidad y/o servir como una forma de apropiación del paisaje.

El quinto sitio con grabados es LD-S7, formado por cuatro sectores: dos con recintos pircados circulares agrupados, uno con un recinto pircado aislado mayor $(6 \times 4 \mathrm{~m})$, y el sector con los grabados (LD-S7C). Uno de los bloques grabados presenta cuatro figuras: una línea con ángulo recto hecha mediante un piqueteado lineal profundo; dos areales - una triangular pequeña semejante a un tridígito y otra rectangular no figurativa, muy degradada-; y una ancoriforme (cuadrangular de lados curvos). Esta última, vertical y de $10 \mathrm{~cm}$ de alto, ha sido manufacturada a partir de piqueteado areal; ocupa el área central del panel y está cerca de la rectangular, aunque no se puede establecer una asociación directa entre ambas (Figura 12). En las cercanías al recinto mayor, existe otro soporte menor cuyo panel con orientación cenit también presenta grafías: una línea recta de $15 \mathrm{~cm}$, efectuada mediante abrasión, y un mortero pequeńo o cupulita de $8 \mathrm{~cm}$ de diámetro. La visibilidad de estas marcas está dada por su profundidad, no por generar contraste entre fondo y figura. LD-S7 se emplaza a metros de la línea de costa antigua de una laguna de agua dulce menor, ubicada a $1500 \mathrm{~m}$ de la ladera septentrional del volcán Maipo y a $10 \mathrm{~km}$ al este de los pasos Alvarado.

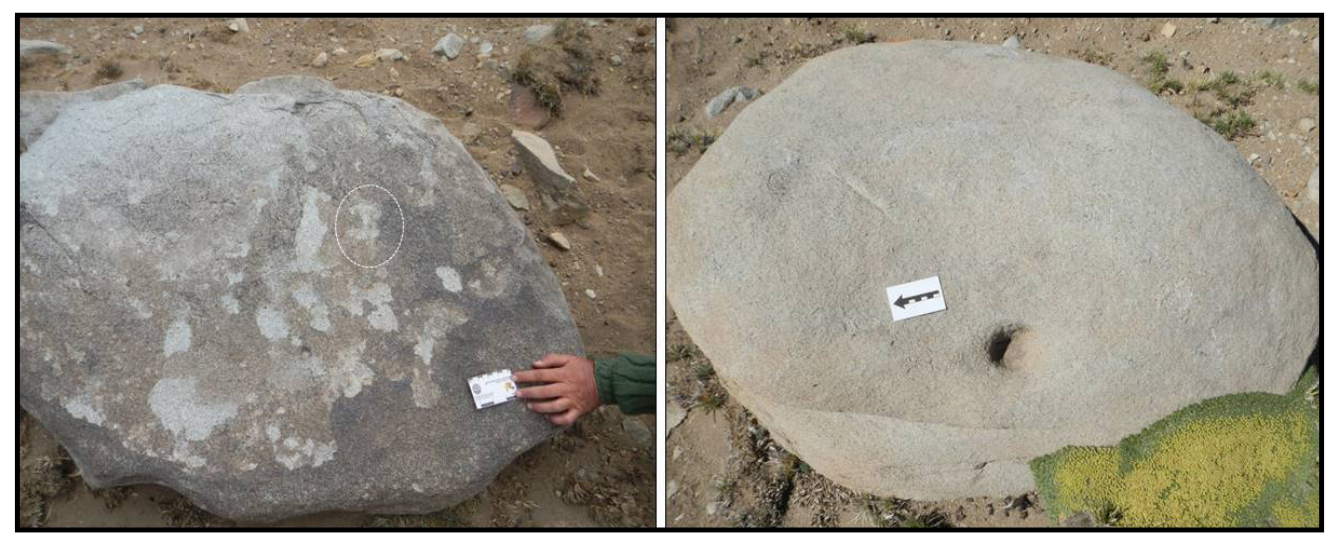

Figura 12. Soportes del sitio LD-S7C.

A la izquierda, soporte con figura ancoriforme (rodeada por un círculo); a la derecha, soporte con cupulita y línea recta. 
La figura ancoriforme de LD-S7C sirve también para ubicar cronológicamente las manifestaciones de arte rupestre de ANPLD, ya que figuras semejantes han sido asignadas al arte rupestre del Período Tardío en centro-norte de Chile y en el centro-oeste argentino (García, 2014; Zárate et al., 2020). Se los asocia a tumis, y se los vincula a símbolos de poder incorporados en épocas del dominio incaico, tanto en el norte de Chile (Montt y Pimentel, 2003) como en el Noroeste Argentino (Hernández Llosas, 2006; Martel y Giraudo, 2014).

Por último, se considera el arte rupestre de la localidad Arroyo Campos Borbarán (Bárcena, 2003, 2010). Aunque la descripción publicada no permite un acercamiento preciso a las características de sus petroglifos, da cuenta de figuras cuadrangulares y "signos escudo" -motivos estándar dentro del arte rupestre inca del centro de Chile (Troncoso, 2001)-.

\section{Discusión}

Para entender la forma en que las sociedades prehispánicas hicieron uso de las cuencas cordilleranas altas de los ríos Maipo y Diamante, se ha adherido a un modelo de complementariedad ecológica $^{4}$ derivado del de Murra (1975), que propone que, en ambientes andinos, la supervivencia de sociedades con economías de caza y recolección y agropastoriles se basó en la complementación anual de recursos provenientes de distintos pisos altitudinales (Durán y García, 1989). Dentro de un marco con estas características, resulta inadecuado categorizar cualquiera de esos pisos como marginal/pobre o central/rico, ${ }^{5}$ ya que es la oferta del conjunto total la que importa. Teniendo en cuenta lo expuesto, se ha considerado que los ambientes de altura de la cordillera Principal, en la franja latitudinal tomada, fueron ocupados estacionalmente durante todo el Holoceno, primero por cazadores-recolectores y luego, a partir del $2000 \mathrm{AP}$, por grupos agropastoriles del PAT, PIT y PT de la cuenca cordillerana del río Maipo. Se entiende que estas sociedades pudieron crecer demográficamente y pasar por un proceso de intensificación que las llevó a hacer un uso cada vez más prolongado de las tierras altas, con el objeto de asegurar el rendimiento de sus actividades pastoriles y de caza y recolección. Esta cordillera ocupada por pastores pudo favorecer la circulación de bienes a través de mecanismos de tráfico de tipo incorporado y/o especializado. El primero, desarrollado por pastores individuales y el segundo, por individuos especializados dentro de las comunidades pastoriles (Nielsen, 2006; Yacobaccio, 2012). Esta manera de ver el proceso de poblamiento humano de la región se contrapone a otras que entienden que los ambientes de altura considerados se mantuvieron siempre ocupados por cazadores-recolectores, aun durante el período en el que el valle central chileno y el centro-oeste y noroeste de Mendoza se anexaron al Tawantinsuyu (Cornejo y Sanhueza 2011a; Neme et al., 2016; Morgan et al., 2017). También se contrapone a una propuesta muy arraigada en la arqueología chilena que considera que el pastoreo de camélidos se inicia en el valle central con la conquista incaica ${ }^{6}$ (Falabella, Pavlovic, Planella y Sanhueza, 2016).

4 El modelo de complementariedad de pisos ecológicos elegido tiene mayor correspondencia con el inicial de base claramente funcionalista/adaptacionista (Murra, 1975). Pero también se han tenido en cuenta propuestas de arqueología internodal realizadas en ambientes puneńos (Nielsen, 2006).

5 Se asume una posición crítica a la propuesta de Neme $(2007,2016)$ que considera las tierras altas de cordillera un ambiente marginal y, por serlo, que fue ocupado en forma tardía.

6 Al aplicar el método osteológico/anatómico de Becker a registros arqueofaunísticos preincas de Chile central, no se ha podido determinar la presencia de Lama glama. Pero hay otros indicadores en esos registros que permitirían proponer prácticas de pastoralismo. Por ejemplo, para el PIT se ha registrado un incremento en la frecuencia de camélidos y que algunos fueron alimentados con maíz (Falabella et al., 2016; Pavlovic et al., 2019). 
El objetivo principal de este trabajo es probar que las cuencas cordilleranas altas de los ríos Diamante y Maipo fueron controladas por el Estado inca. Para ello se llevaron adelante distintas líneas de investigación en ANPLD. Los resultados obtenidos muestran que las cronologías, tanto de los sitios del área como de otros próximos, corresponden al inicio del período de consolidación del dominio incaico del valle central chileno y el noroeste y centro-oeste de Mendoza -1450-1500 años DC- (Cornejo, 2014; Marsh et al., 2017). También ha podido demostrarse que este período muestra una mayor intensidad de uso de los sitios, que se percibe claramente al cuantificar el volumen de lascas proximales y al comparar los valores obtenidos con los de ocupaciones previas. Esta mayor intensidad de ocupación tiene un correlato en los índices de densidad de cerámica de tipos incaicos que resultan similares a los de contextos incas del valle central chileno (Cornejo y Saavedra, 2018). Se da en ANPLD, al mismo tiempo, un incremento de la presencia de Camelidae. Si se asocia a esta información el aumento considerable de taxones de especies vegetales provenientes de pisos de vegetación más bajos (predominantes de la vertiente occidental), puede considerarse que la ejecución de esta estrategia preascenso de aprovisionamiento de leña fue una consecuencia de la disminución de la oferta de leńas locales, provocada por ese incremento en la intensidad de uso. La identificación de Lama glama en el registro arqueológico de LD-S4 permitiría proponer la utilización de animales de carga para el traslado de distintos recursos desde y hacia la vertiente occidental. El aprovisionamiento de leña en ambientes más bajos para equipar los emplazamientos de verano y su transporte en llamas puede considerarse un comportamiento más viable que el acarreo humano, en lo que hace a energía invertida. Por otra parte, el registro de estos animales es un claro argumento a favor de la presencia de pastores. El interrogante que surge es si estos pastores ingresaron a ANPLD siguiendo una actividad trashumante tradicional, sin ser controlados por el Estado inca, o si, por el contrario, fue una actividad supervisada y controlada por ese Estado para favorecer, por ejemplo, el funcionamiento de mecanismos de tráfico caravanero especializado.

$\mathrm{Al}$ incorporar en este escenario el caravaneo, cobran otro sentido las características arquitectónicas y la distribución en el espacio de los recintos pircados presentes en ANPLD y regiones vecinas. Su forma de construcción y diseño (plantas circulares, semicirculares o irregulares, próximas o adosadas a grandes bloques, con muros simples de pirca seca y alturas bajas) es semejante a los que han dejado los caravaneros en la puna chilena, boliviana y argentina (Nielsen, 2006; Pimentel, Montt, Blanco y Reyes, 2007; Yacobaccio, 2012). El tránsito con llamas de estos caravaneros actuales requiere lugares para pasar una noche (jara), después de hacer movimientos diarios de entre 15 y $25 \mathrm{~km}$, y de otros mejor equipados (jarana de ocupación prolongada ${ }^{7}$ ) que se emplazan en lugares con recursos vitales (leña, agua y forraje) en donde se permanece uno o más días con el objeto de recuperar la energía de los animales o para prepararlos para un esfuerzo mayor, como el paso por un portezuelo (Nielsen, 2006; Martel, Zamora y Lépori, 2017). Si se observa con esta perspectiva la distribución, características y conectividad de los sitios de ANPLD y de localidades próximas de la vertiente oriental (Risco de Indios, El Indígeno y Arroyo Campos Borbarán) y occidental (Vega Linda, Buena Vista, Cruz de Piedra y Puente de Tierra), puede reconocerse que forman parte de una red vial amplia y compleja. En esa red estos sitios pudieron funcionar como lugares de permanencia corta o prolongada de acuerdo a sus características contextuales y/o a las decisiones y necesidades de quienes circulaban.

7 En las jaranas de ocupación prolongada suelen aparecer estructuras mayores en forma de U que se utilizan para controlar y cargar los animales (Nielsen, 2006). Una estructura con estas características ha sido registrada en El Indígeno (Neme, 2016, Fig. 6, p. 104). 
En su conjunto, ANPLD tiene características extraordinarias: extensas mesetas, con alturas comprendidas entre los 3300 y $3400 \mathrm{msnm}$, con la mayor laguna de agua dulce de la región y varias menores, además de arroyos y surgentes y una oferta destacable de recursos vegetales y animales. Debe sumarse a estas características ventajosas su proximidad al paso del Maipo, el más bajo y amplio de la región (Cornejo y Sanhueza, 2011a). Se entiende que fue, por ello, un lugar obligatorio de tránsito para aquellos que se movían sobre la red de sendas que surcaban la cordillera en sentidos norte-sur y este-oeste y, al mismo tiempo, un lugar óptimo para establecimientos estacionales de pastores.

También el registro intrasitio muestra evidencias que podrían asociarse a tráfico especializado. Para el caso específico de la obsidiana, la variabilidad de fuentes marca un punto de inflexión en lo referido a estrategias de interacción interregional. Se halla presente la mayor parte de las fuentes externas cordilleranas y extracordilleranas registradas (cinco), mientras que en períodos anteriores solo aparecen dos. Ya que el aumento en la circulación de obsidiana para el Período de Desarrollos Regionales ha sido propuesto como una prueba de tráfico especializado en el NOA (Yacobaccio, 2012), se entiende que puede hacerse una inferencia similar para ANPLD. Para este supuesto sistema de tráfico, se destaca un flujo sur-norte de obsidiana desde fuentes ubicadas a cientos de kilómetros y totalmente vinculadas a la cuenca del río Grande. Este valle es predominantemente latitudinal y conforma con las nacientes de los ríos Atuel y Diamante un corredor natural que conecta la cordillera sur de Mendoza con la central. Al considerar el funcionamiento de esa red, resulta sugerente no haber encontrado en los registros de ANPLD obsidiana de la fuente El Peceño, que se ubica en las planicies orientales. Ya que es de allí de donde procederían los cazadores-recolectores que, según el modelo de base etnohistórica, ocupaban la cuenca cordillerana alta del río Diamante y manejaban el tráfico de bienes entre ambas vertientes durante el período considerado. Por otra parte, el flujo de bienes con dirección norte-sur y este-oeste también podría inferirse a través de la cerámica negra pulida y la gris incisa, que procederían del norte semiárido chileno y el noroeste y centro-oeste de Mendoza, respectivamente.

Se ha señalado que fue una política del Estado inca controlar las rutas de circulación de bienes, entre ellos la obsidiana (Bray, 1992; Stehberg 1995; Yacobaccio, Escola, Lazzari y Pereyra, 2002; Ogburn, Connell y Gifford, 2009). En este sentido, el registro de ANPLD parece marcar que el Estado no solo controló el funcionamiento del tráfico que practicaban las sociedades locales del valle del Maipo, sino que pudo potenciarlo a través de caravaneros especializados. Se considera posible, además, que la mayor importancia otorgada por los incas a esta materia prima haya hecho que se diera una explotación más intensa de la cantera/taller ubicada en ANPLD. Las características del sitio asociado (LD-S21) y la presencia de un bloque con motivos serpentiformes (LD-S23) dentro de la propia cantera muestran claramente que se dio un control o algún tipo de apropiación estatal sobre ese recurso.

La apropiación estatal de las cuencas cordilleranas altas de los ríos Maipo y Diamante también puede proponerse a través del arte rupestre. Por las características de los motivos descriptos y de sus emplazamientos se considera que corresponden al Período Inca y son la materialización visual de una forma de pensamiento (Troncoso, 2008). En ANPLD, quienes ejecutaron estas figuras de clara filiación incaica debieron compartir un código común que les permitiera comprender el mensaje. Sus autores pudieron ser miembros de poblaciones de la cuenca cordillerana del río Maipo o foráneas. Para ambos casos se entiende que agentes imperiales debieron trasladarse hasta la zona para ejecutar o apreciar el mensaje. Con el objeto de inferir la función de estas grafías se utiliza el concepto de paisaje conquistado, que sería una estrategia de marcación 
del espacio a partir de las grafías rupestres. Esta estrategia estaría inserta en un proceso implícito más amplio de sacralización del paisaje, "[...] en función de la cosmología del grupo dominante que está intentando 'apropiarse culturalmente' de estos nuevos dominios" (Hernández Llosas, 2006, p. 23). Con base en lo expuesto, se considera posible que en ANPLD el Estado inca haya resignificado ese espacio al construir nuevos emplazamientos con grafías rupestres, con el objeto de imponer su ideología (Troncoso, 2008; Salatino, 2011).

Las características particulares de los motivos serpentiformes permiten discutir otras aproximaciones. Cruz (2015) relaciona los serpentiformes del sur de Bolivia con la figura de Illapa, deidad andina asociada al rayo, con un fuerte vínculo con la actividad minera y con la sacralidad de los cerros o Apus. A la par, se vincula a Illapa con la práctica pastoril y se lo considera propiciador de la fertilidad agrícola, animal y humana; y es también una deidad guerrera, legitimadora de linajes y fuente de sabiduría para curanderos (Baulenas i Pubill, 2016).

Complementariamente, los serpentiformes de ANPLD pueden vincularse a Amaru, la serpiente del agua -de hecho la forma de desplazarse de esta serpiente coincide con la del rayo al caer en la tierra (Baulenas i Pubill, 2012)-. Esta deidad forma parte de la cosmología andina y se asocia a los ancestros, el cielo, la tierra, los ríos, las quebradas, la lluvia, los canales de riego, las cuevas, la fertilidad y la procreación (Hernández Llosas, 2006). Teniendo en cuenta esto último, se podría sugerir que los serpentiformes se ejecutaron tomando la laguna del Diamante o a las nacientes del río Diamante como una expresión de esa deidad. Las lagunas de magnitud eran consideradas pacarinas, y aún más aquellas que tenían en su proximidad grandes volcanes como el Maipo, posible $A p u$, cuyas condiciones de visibilización son extraordinarias.

\section{Conclusión}

Se contrastó en forma positiva la hipótesis propuesta sobre el control del Estado inca de las cuencas cordilleranas altas de los ríos Maipo y Diamante. También se ha obtenido información que permite definir los posibles propósitos de ese control y discutir el origen de los agentes encargados de realizar las actividades acordadas o impuestas por el Estado. La explotación de una fuente de obsidiana fue una de esas actividades $y$, probablemente la principal, mantener en funcionamiento una red de tráfico trans e intercordillerano y su infraestructura. Esta red conectaba el valle central chileno con los valles de Jaurúa y Uco, que estaban dentro de las fronteras del Estado y se introducía hacia el sur, por los valles longitudinales intercordilleranos, con el propósito de obtener bienes que habían adquirido un nuevo valor y significado. Entre ellos, la obsidiana seguramente ocupó un lugar destacado. Se entiende que fueron sociedades agropastoriles de la vertiente occidental (de la cuenca del río Maipo en particular para la franja cordillerana considerada) las encargadas de realizar esas actividades. Por otra parte, se propone que el Estado inca sacralizó el espacio que incluye la laguna del Diamante y el volcán Maipo. Los registros arqueológicos que reflejan esta apropiación simbólica han comenzado a encontrarse al poner en discusión modelos de poblamiento de la región que niegan considerar la posibilidad de su existencia.

\section{Agradecimientos}

Este trabajo se realizó con fondos procedentes del CONICET (PIP. Res. 0111/2016), la Agencia Nacional de Promoción Científica y Técnica (PICT-2014-0940, PICT-2015-3802 y PICTO-2016-0056), la Universidad Nacional de Cuyo (Proyecto SIIP, 2019, 06/G797) y la 
National Geographic Society (HJ-136R-17). Se agradece a los evaluadores y editores de la revista Estudios Atacameños. Arqueología y Antropología Surandinas. Se expresa un agradecimiento especial a la Dirección de Recursos Naturales del Gobierno de la Provincia de Mendoza y a los guardaparques del Área Natural Protegida Laguna del Diamante.

\section{Referencias citadas}

Andrefsky, W. (1998). Lithics: macroscopic approaches to analysis (Second). New York, NY: Cambridge University Press.

Andreoni, D. (2015). Estudio Antracológico en la Alta Cordillera Mendocina (Argentina): El caso del sitio El Indígeno y sus Implicancias a Nivel Macro-Regional. Revista Chilena de Antropología, 32(2), 39-56.

Andreoni, D. y Capparelli, A. (2012). El ser humano y la leña en la cordillera de Mendoza (Argentina), a lo largo del Holoceno: sitio arqueológico Arroyo Malo 3. Magallania, 40(1), 199-224.

Andreoni, D. y Durán, V. (2021). Estrategias de manejo de plantas leñosas en ambientes de altura. Área Natural Protegida Laguna del Diamante (Mendoza, Argentina). Latin American Antiquity. Aceptado para su publicación.

Barberena, R., Tessone, A., Cagnoni, M., Gasco, A., Durán, V., Winocur, D., .. E. Gautier (2019). Bioavailable Strontium in the Southern Andes (Argentina and Chile): A Tool for Tracking Human and Animal Movement. Environmental Archaeology, 24(2). https://doi.org/10.1080/14614103.2019.1689894

Bárcena, J. R. (1992). Datos e interpretación del registro documental sobre la dominación incaica en Cuyo. Xama, 4-5,11-49.

Bárcena, J. R. (1998). El tambo Real de Ranchillos, Mendoza, Argentina. Xama, 6,1-52.

Bárcena, J. R. (2003). Nota sobre un nuevo sitio con grabados rupestres en el Departamento de San Carlos, Provincia de Mendoza. Reconocimientos arqueológicos en la Estancia Tierras Blancas. Relaciones de la Sociedad Argentina de Antropologia, XXVIII, 241-251.

Bárcena, J. R. (2010). Dataciones por radiocarbono en el sector con grabados rupestres del arroyo Campos Borbarán (Estancia Tierras Blancas, departamento de San Carlos, Provincia de Mendoza). Xama Serie Monografias, 17-46.

Baulenas i Pubill, A. (2012). La divinidad Illapa en el panteón imperial incaico. Investigaciones sociales, 16(28), 333-341.

Baulenas i Pubill, A. (2016). La divinidad Illapa en la dicotomía Hanan/Hurin Cusco. En Alcántara, García y Sánchez (Coords.). Arqueología. Memoria del $56^{\circ}$ Congreso Internacional de Americanistas (pp. 291-299). Salamanca: Ediciones de la Universidad de Salamanca.

Bray, T. (1992). Archaeological survey in northern Highland Ecuador: Inca imperialism and the País Carachi. World Archaeology, 24(2), 218-233.

Bronk Ramsey, C. (2009). Bayesian Analysis of Radiocarbon Dates. Radiocarbon, 51, 337-360.

Cahiza, P. y Ots M. J. (2005). La presencia inka en el extremo sur oriental del Kollasuyo. Investigaciones en las tierras bajas de San Juan y Mendoza, y el Valle de Uco -Rca. Argentina. Xama, 15-18, 217-228. 
Cartajena, I., Núñez, L. y Grosjean, M. (2007). Camelid domestication in the westem slope of the puna de Atacama, northem Chile. Anthropozoologica, 42(2), 155-173.

Cornejo, L. (2008). El sitio inka Puente de Tierra (Alto río Maipo, Chile) y la frontera sur del Tawantinsuyu. Revista Clava, 7, 73-84.

Cornejo, L. (2014). Sobre la cronología de la imposición cuzqueña en Chile. Estudios Atacameños. Arqueología y Antropologia Surandinas, 47, 101-116.

Cornejo, L., Miranda, P. y Saavedra, M. (1999). Cabeza de León: ¿una localidad de explotación minera prehispánica en la Cordillera Andina de Chile Central? Chungara. Revista de Antropología Chilena, 29(1), $7-17$.

Cornejo, L., Saavedra, M. y Vera, H. (2006). Nuevos registros de asentamientos inka en la Cordillera Andina de Chile Central. Boletín de la Sociedad Chilena de Arqueología, 39, 7-18.

Cornejo, L. y Saavedra, M. (2018). El centro político inka en el extremo austral del Tawantinsuyu (Chile Central). Boletín del Museo Chileno de Arte Precolombino, 23(1), 133-158.

Cornejo, L. y Sanhueza, L. (2011a). Caminos que cruzan la cordillera: El rol del paso del Maipo en la ocupación de la cordillera en Chile Central. Revista Chilena de Antropología, 23, 101-122.

Cornejo, L. y Sanhueza, L. (2011b). North and South: Hunter-gatherer communities in the Andes Mountains in Central Chile. Latin American Antiquity, 22(4), 487-504.

Cortegoso, V., Barberena, R., Durán V. y Lucero G. (2016). Geographic vectors of human mobility in the Andes (34-36 $\mathrm{S})$ : comparative analysis of 'minor' obsidian sources. Quaternary International, 422, 81-92.

Cortegoso, V., Yebra, L., Durán, V., Barberena, R., Lucero, G., Cornejo, L., ... Glascock, M. (2020). Obsidian sources from the southern Andean highlands (Laguna del Diamante, Argentina and Chile): geochemical insights on geological complexity and human biogeography. Archaeological and Anthropological Sciences, 12, art. num. 29.

Cruz, P. (2015). Tatala Purita o el influjo del Rayo. Arte rupestre anicónico en las Altas Tierras Surandinas (Potosí, Bolivia). Boletín SIARB, 29, 51-70.

Dalmasso, A., Martínez Carretero E., Videla F. y De Lugan, M. (1996). Las áreas protegidas de Mendoza. Su relación con la conservación. En Martínez Carretero, E. y Damasso, A. (Eds.). Mendoza Ambiental (pp. 267-276). Mendoza: IADIZA - Gobierno de Mendoza.

Durán, V. (2000). Poblaciones Indigenas de Malargüe. Su arqueología e Historia. Mendoza: CEIDER. Serie Libros No 1.

Durán, V., Cortegoso, V., Barberena, R., Novellino, P., Frigolé, C., Lucero, ... y Yebra L. (2018). To and fro the Andean highlands (central Argentina and Chile): Archaeometric and geographic insights on human movility. Journal of Archaeological Sciences: Reports, 18, 668-678.

Durán, V. y García, C. (1989). Ocupaciones agro-alfareras en el sitio Agua de la Cueva-sector norte (NO de Mendoza). Revista de Estudios Regionales (CEIDER), 3, 29-64.

Durán, V., Gasco, A., Paiva, J., Zonana, M. y Barberena, R. (2020). El aprovechamiento de camélidos y ambientes de altura en sociedades agropastoriles prehispanas del NO de Mendoza. Relaciones de la Sociedad 
Argentina de Antropología, XLV(2), 271-296.

Durán, V., Neme, G., Gil, A. y Cortegoso, V. (2006). Arqueología del Área Natural Protegida Laguna del Diamante (Mendoza, Argentina). Anales de Arqueología y Etnología, 61, 81-134.

Elmi, C., Chen, J., Goldsby, D. y Gieré, R. (2017). Mineralogical and compositional features of rock fulgurites: A record of lightning effects on granite. American Mineralogist, 102(7), 1470-1481.

Falabella, F., Pavlovic, D., Planella, M. y Sanhueza, L. (2016). Diversidad y heterogeneidad cultural y social en Chile central durante los períodos Alfarero Temprano e Intermedio Tardío (ca. 300 A.C. - 1.450 d.C.). En Falabella, F., Uribe, M., Sanhueza, L., Aldunate, C. e Hidalgo, J. (Eds.). Prehistoria en Chile: desde sus primeros habitantes hasta los Incas (pp. 365-400). Santiago: Editorial Universitaria.

Falabella, F., Sanhueza, L., Neme, G. y Lagiglia, H. (2001). Análisis comparativo de cerámica Aconcagua entre Chile y Argentina. Relaciones de la Sociedad Argentina de Antropología, 26, 193-214.

Frigolé, C., Sanhueza, L., Riera Soto, C., Falabella, F., Menzies, A. y Barraza, M. (2018). Análisis de tecnología de pastas cerámicas provenientes de las vertientes oriental y occidental de la Cordillera de Los Andes (200-1000 DC). Libro de Resúmenes XXI Congreso Nacional de Arqueología Chilena. Santiago.

García, E. A. (2004). La cronología del estilo cerámico Agrelo y sus implicancias para el estudio de las sociedades tardías de Mendoza. Revista de Estudios Regionales (CEIDER), 26, 29-39.

García, E. A. (2011). El control incaico de las Tierras Bajas Cuyanas. Una evaluación del modelo de enclaves. Sociedades de Paisajes Áridos y Semi-áridos. III(IV), 39-62.

García, E. A. (2014). Los petroglifos del Cerro Blanco de Zonda (San Juan). Comechingonia, 18(2),161-180.

Gasco, A. (2013). Caza y pastoreo de camélidos en la frontera meridional del "mundo" andino. Una aproximación osteométrica. Tesis doctoral. Facultad de Filosofía y Humanidades, Universidad Nacional de Córdoba, Argentina.

Gasco, A. (2014). Familia Camelidae: variabilidad métrica actual y gradiente de tamaño corporal. En Cortegoso, V., Durán, V. y Gasco, A. Arqueología de ambiente de altura de Mendoza y San Juan (Argentina) (pp. 307-559). Mendoza: EDIUNC.

Hernández Llosas, M. (2006). Inkas y españoles a la conquista simbólica del territorio de Humahuaca: sitios, motivos rupestres y apropiación cultural del paisaje. Boletín del Museo Chileno de Arte Precolombino, $11(2), 9-34$.

Hiscock, P. (2002). Quantifying the size of artefact assemblages. Journal of Archaeological Science, 29(3), 251-258.

Hogg, A., Hua, Q., Blackwell, P., Niu, M., Buck, C., Guilderson, T., ... Reimer, R. W. (2013). SHCal13 Southern Hemisphere Calibration, 0-50,000 cal yr BP. Radiocarbon, 55, 1889-1903.

Hyslop, J. (1984). The Inka Road System. New York, NY: Academic Press.

Ibacache, S. y Cantarutti, G. (2003). Arqueología de montaña en el Cajón del Maipo: El caso del adoratorio incaico del Cerro Peladeros. En XVI Congreso Nacional de Arqueología Chilena, Simposio Avances en la Arqueología de Chile Central. Sociedad Chilena de Arqueología. Museo de Historia Natural de Concepción. 
Izeta, A. (2009). Introducción al dossier: Osteometría de camélidos. Aportes metodológicos desde la arqueología sudamericana. Revista del Museo de Antropología, 2, 125-126.

Jones, B., Jones, K., Rambo, K., Rakov, V., Jerald, J. y Uman, M. (2005) Oxide reduction during triggeredlightning fulgurite formation. J Atmos Solar-Terres Phys 67, 423-428

Lagiglia, H. (1999). Arqueologia de Cazadores-Recolectores Cordilleranos de Altura. Mendoza: ICN. Ediciones Ciencias y Arte.

Lucero, G., Castro, S., Marsh, E. y Cortegoso, V. (2016). Costos de explotación de recursos líticos en ambientes de altura (NO de San Juan, Argentina). Una propuesta metodológica SIG: 2925-2931. Actas del XIX Congreso Nacional de Arqueología. Tucumán, Argentina.

Luebert, F. y Pliscoff, P. (2017). Sinopsis bioclimática y vegetal de Chile. Santiago de Chile: Editorial Universitaria.

Madrid, J. (1977). Ocupación indigena en el valle superior del rio Maipo. Tesis de licenciatura en Arqueología Prehistórica. Universidad de Chile, Santiago de Chile.

Marsh, E., Kidd, J., Ogburn, R. y Durán, V. (2017). Dating the Expansion of the Inca Empire: Bayesian Models from Ecuador and Argentina. Radiocarbon, 59, 117-140.

Martel, Á. y Giraudo, S. (2014). Semiótica de la imagen en Arqueología: el caso de los 'escutiformes'. Revista Chilena de Antropología Visual, 24, 21-45.

Martel, A., Zamora, D. y Lépori, M. (2017). Tráfico y movilidad caravanera en la Puna catamarqueña. Una mirada internodal. Estudios Atacameños. Arqueología y Antropología Surandinas, 56, 197-223.

Michieli, C. (1994). Antigua Historia de Cuyo. San Juan: Ansilta.

Michieli, C. y Gambier, M. (1998). Estaciones de grupos chilenos tardíos en la alta cordillera del sudoeste de San Juan, Argentina. Publicaciones, 22 (nueva serie), 3-53.

Montt, I. y Pimentel, G. (2003). Grabados antropomorfos tardíos. El caso de las personificaciones de hachas en San Pedro de Atacama (Norte de Chile). En Sepúlveda, M., Chacama, J. y Briones, L. (Eds.). Crónicas sobre la piedra. Arte Rupestre de Las Américas. Arica: Universidad de Tarapacá.

Morgan, C., Neme, G., Sugrañes, N., Salgan, L., Gil, A., Otaola, C., Giardina, M. y Llano, C. (2017). Late Prehistoric High-Altitude Hunter-Gatherer Residential Occupations in the Argentine Southern Andes. Journal of Field Archaeology, 42, 214-227.

Murra, J. (1975). Formaciones económicas y políticas del Mundo Andino. Lima: Instituto de Estudios Peruanos.

Nami, H. (1992). El subsistema tecnológico de la confección de instrumentos líticos y explotación de los recursos del ambiente: una nueva vía de aproximación. Shincal, 2(2), 33-53.

Neme, G. (2007). Cazadores-recolectores de Altura en los Andes Meridionales: El Alto Valle del Rio Atuel. Oxford: BAR International Series 1591.

Neme, G. (2016). El Indígeno and high-altitude human occupation in the southern Andes, Mendoza (Argentina). Latin American Antiquity, 27, 96-114. 
Neme, G., Otaola, C., Giardina, M., Gil, A. y Franchetti, F. (2020). Consumo de fauna y funcionalidad de sitios: testeando hipótesis en los Andes Meridionales. Latin American Antiquity, 31(1), 163-179.

Neme, G., Sugrañes, N., Salgán, L., Gil, A., Otaola, C., Giardina, M., Morgan, C. y Llano, C. (2016). Risco de los indios: Ocupaciones humanas de altura en la cuenca del río Diamante. Relaciones de la Sociedad Argentina de Antropología, 41, 101-130.

Nielsen, A. (1997). El tráfico caravanero visto desde la Jara. Estudios Atacameños, 14, 339-371.

Nielsen, A. (2006). Estudios internodales e interacción interregional en los Andes circumpuneños: teoría, método y ejemplos de aplicación. En Lechtman, H. (Ed.). Esferas de interacción prehistóricas y fronteras nacionales modernas: los Andes sur centrales (pp. 29-69). Lima: IEP - IAR.

Nuñez, T., Lawler, J., McRae, B., Pierce, D., Krosby, M., Kavanagh, D., Singleton, P. y Tewksbury, J. (2013). Connectivity Planning to Address Climate Change. Conservation Biology, 27(2), 407-416.

Ogburn, D., Connell, S. y Gifford, C. (2009) Provisioning of the Inka army in wartime: obsidian procurement in Pambamarca, Ecuador. Journal of Archaeological Science, 36, 740-751.

Ots, M. J. (2009). La población tardía del Valle de Uco y la dominación incaica en la frontera suroriental del Qollasuyu. En Martini, Y., Pérez Zavala, G. y Aguilar, Y. (Comps.). Las sociedades de los paisajes áridos y semiáridos del Centro-Oeste Argentino (pp. 133-149). Río Cuarto: Universidad Nacional de Río Cuarto.

Pasek, M. A., Block, K. y Pasek, V. (2012). Fulgurite morphology: a classification scheme and clues to formation. Contributions to Mineralogy and Petrology, 164(3), 477-492.

Pavlovic, D., Sánchez, R., Pascual, D., Martínez, A., Cortés, C., Ávila, C. y La Mura, N. (2019). Rituales de la vida y la muerte: dinámicas e interacción entre el Tawantinsuyu y las poblaciones locales en la cuenca del Maipo-Mapocho, Chile Central. Estudios Atacameños. Arqueología y Antropología Surandinas, 63, 43-80.

Pavlovic, D., Troncoso, A., Sánchez, R. y Pascual, D. (2012). Un Tigre en el Valle. Vialidad, Arquitectura y Ritualidad Incaica en la Cuenca Superior del Río Aconcagua Arica. Chungara. Revista de Antropología Chilena, 44(4), 551-569.

Pimentel, G., Montt, I., Blanco, J., y Reyes, A. (2007). Infraestructura y prácticas de movilidad en una ruta que conectó el Altiplano boliviano con San Pedro de Atacama (II Región, Chile). En Nielsen, A. (Comp.). Producción y circulación prehispánicas de bienes en el Sur Andino (pp. 351-387). Córdoba: Editorial Brujas.

Prieto, M. R. (1989). La frontera meridional mendocina durante los siglos XVI y XVII. Xama, 2, 117-132.

Rancusi, M., Nishida, M. y Nishida, H. (1987). Xylotomy of Important Chilean Woods. En Makoto, N. (Ed.). Contributions to botany in the Andes II (pp 68-158). Tokio: Academy Scientific Book.

Salatino, P. (2011). Semiótica, paisaje social y arte rupestre de época incaica en la cuenca superior del Río Aconcagua, Chile Central. Arqueología, 18, 209-234.

Sánchez, R. (2004). El Tawantinsuyo en Aconcagua (Chile Central). Chungara. Revista de Antropología Chilena, 36, 325-336.

Sanhueza, L., Falabella, F., Fonseca, E. y Andonie, O. (2004). Aplicación de análisis de pastas macroscópicos, petrográficos y de composición de elementos químicos al problema de la procedencia de cerámica 
en el Período Alfarero Temprano de Chile central y Cuyo, Argentina. Estudios Atacameños, 28, 121-132.

Schobinger, J. (Comp.). (2001). El santuario incaico del cerro Aconcagua. Mendoza: EDIUNC.

Scotti, A., Durán, V. y Lecitra, R. (2012). Oferta nutritiva para Lama guanicoe, bóvidos y caprinos de vegas del valle El Peñón, en la región del Complejo Volcánico Planchón-Peteroa, Malargüe, Mendoza, Argentina. En Armeite, M. y Molina, M. (Comps.). Actas Trabajos Completos E-ICES 7 (pp. 313-319). Buenos Aires: Comisión Nacional de Energía Atómica.

Silva, O. (1985). La expansión Incaica en Chile, problemas y reflexiones. Actas del IX Congreso Nacional de Arqueología, 321-244.

Sruoga, P., Etcheverría, M., Folguera, A., Repol, D. y Zanettini, J. (2004). Hoja Geológica 3569-I. Volcán Maipo, provincia de Mendoza. Boletín Servicio Geológico Minero Argentino, 290, 1-116.

Stehberg, R. (1995). Instalaciones incaicas en el Norte y Centro Semiárido de Chile. Santiago de Chile: Centro de Investigaciones Diego Barros Arana, DIBAM.

Stehberg, R., Prado, C. y Rivas, P. (2017). El sustrato incaico de la Catedral Metropolitana (Chile). Boletin del Museo Nacional de Historia Natural, 66(2), 161-208.

Stehberg, R. y Sotomayor, G. (2012). Mapocho Incaico. Boletín del Museo Nacional de Historia Natural, 61, 85-149.

Sugrañes, N. (2019). Diversidad cerámica del sur de Mendoza. Discutiendo tipologías. Relaciones de la Sociedad Argentina de Antropología, XLIV(1), 57-76.

Troncoso, A. (2001). Sobre el arte rupestre en el Valle de Aconcagua y porqué los signos escudos son incaicos. Actas del Cuarto Congreso Chileno de Antropología. Santiago de Chile.

Troncoso, A. (2008). Arte rupestre en la cuenca del Río Aconcagua: Formas, sintaxis, estilo y poder. Traballos de Arqueoloxia e Patrimonio (TAPA). Santiago de Compostela: Instituto de Estudos Galegos Padre Sarmiento.

Yacobaccio, H. (2012). Intercambio y caravanas de llamas en el Sur andino. Comechingonia, 16, 13-33.

Yacobaccio, H., Escola, P., Lazzari, M. y Pereyra, F. (2002). Long-Distance Obsidian Traffic in Northwestern Argentina. En Glascock, M. (Ed.). Geochemical Evidence for Long-Distance Exchange (pp. 167-203). Londres: Bergin and Garvey.

Yacobaccio, H. y Vilá, B. (2013). La domesticación de los camélidos andinos como proceso de interacción humana y animal. Intersecciones en Antropología, 14, 227-238.

Yebra, L., Cortegoso, V., Marsh, E., De Porras, M., Maldonado, A., Castro, S., Barberena, R. y Durán, V. (2021). Dinámica climática y estrategias humanas en humedales de altura de los Andes Centro Sur $\left(34^{\circ}\right.$ S): patrones diacrónicos en la intensidad de ocupación de la Laguna del Diamante (ca. 2000-500 años AP). Latin American Antiquity (Ms en evaluación).

Zárate Bernardi, S., Puerto Mundt, S. y Marsh, E. (2020). Arte rupestre al sur del Tawantinsuyu: síntesis comparativa de las vertientes oriental y occidental de Los Andes. Cuadernos de Arte Prehistórico, Número Especial 1, 52-88. 